Eurasiatica

Quaderni di studi su Balcani, Anatolia, Iran, Caucaso e Asia Centrale 15

\title{
Armenia, Caucaso e Asia Centrale Ricerche 2020
}

a cura di

Carlo Frappi e Paolo Sorbello

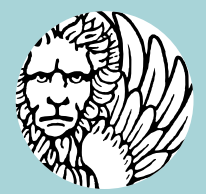

Edizioni

Ca'Foscari

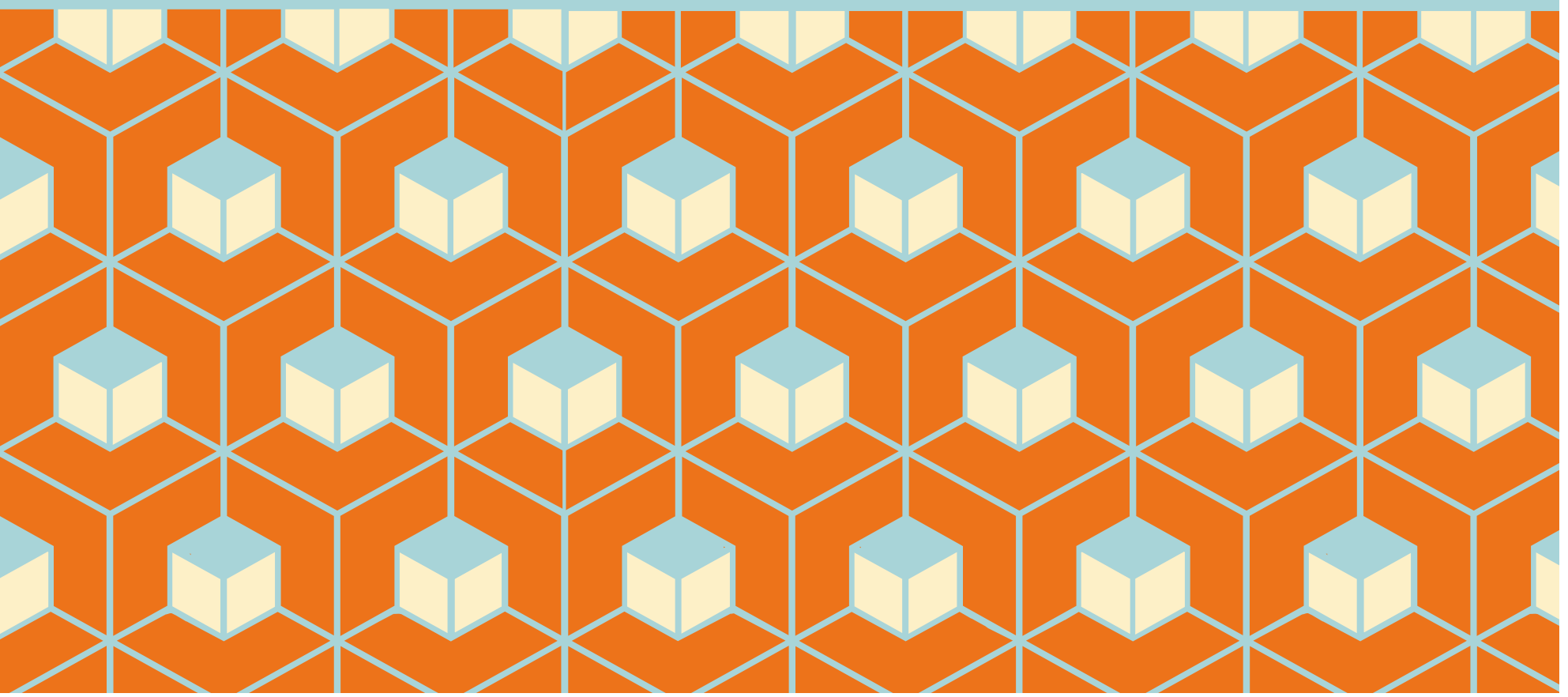


Armenia, Caucaso e Asia Centrale. Ricerche 2020

\section{Eurasiatica}

Serie diretta da

Aldo Ferrari

15

Edizioni

Ca'Foscari 


\title{
Eurasiatica \\ Quaderni di studi su Balcani, Anatolia, Iran, Caucaso e Asia Centrale
}

\author{
Direttore \\ Aldo Ferrari (Università Ca’ Foscari Venezia, Italia)

\section{Comitato scientifico} \\ Gianfranco Giraudo (Università Ca' Foscari Venezia, Italia) \\ Aleksander Naumow (Università Ca' Foscari Venezia, Italia) \\ Antonio Panaino (Alma Mater Studiorum, Università di Bologna, Italia) \\ Valeria Fiorani Piacentini (Università Cattolica del Sacro Cuore, Milano, Italia) \\ Adriano Rossi (Università degli Studi di Napoli «L'Orientale», Italia) \\ Boghos Levon Zekiyan (Università Ca' Foscari Venezia, Italia)
}

\section{Comitato di redazione}

Giampiero Bellingeri (Università Ca' Foscari Venezia, Italia) Giorgio Comai (Osservatorio Balcani e Caucaso Transeuropa/Centro per la Cooperazione Internazionale, Italia) Simone Cristoforetti (Università Ca' Foscari Venezia, Italia) Carlo Frappi (Università Ca' Foscari Venezia) Paolo Lucca (Università Ca' Foscari Venezia) Gianclaudio Macchiarella † (Università Ca' Foscari Venezia, Italia) Stefano Pellò (Università Ca’ Foscari Venezia, Italia) Gaga Shurgaia (Università degli Studi di Napoli «L'Orientale», Italia) Vittorio Tomelleri (Università degli Studi di Macerata, Italia)

\section{Direzione e redazione}

Dipartimento di Studi sull'Asia e sull'Africa Mediterranea

Università Ca' Foscari Venezia

Ca' Cappello, San Polo 2035

30125 Venezia

eurasiatica@unive.it

e-ISSN 2610-9433

ISSN 2610-8879

URL http://edizionicafoscari.unive.it/it/edizioni/collane/eurasiatica/ 


\section{Armenia, Caucaso e Asia Centrale Ricerche 2020}

a cura di

Carlo Frappi e Paolo Sorbello

Venezia

Edizioni Ca' Foscari - Digital Publishing 2020 
Armenia, Caucaso e Asia Centrale. Ricerche 2020

Carlo Frappi, Paolo Sorbello (a cura di)

(C) 2020 Carlo Frappi, Paolo Sorbello peril testo

(C) 2020 Edizioni Ca' Foscari - Digital Publishing per la presente edizione

\section{(1)(1)}

Quest'opera è distribuita con Licenza Creative Commons Attribuzione 4.0 Internazionale This work is licensed under a Creative Commons Attribution 4.0 International License

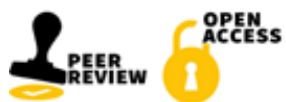

Qualunque parte di questa pubblicazione può essere riprodotta, memorizzata in un sistema di recupero dati o trasmessa in qualsiasi forma o con qualsiasi mezzo, elettronico o meccanico, senza autorizzazione, a condizione che se ne citi la fonte.

Any part of this publication may be reproduced, stored in a retrieval system, or transmitted in any form or by any means without permission provided that the source is fully credited.

Edizioni Ca' Foscari - Digital Publishing

Fondazione Università Ca' Foscari Venezia

Dorsoduro 3246 | 30123 Venezia

http://edizionicafoscari.unive.it/ |ecf@unive.it

1 a edizione ottobre 2020

ISBN 978-88-6969-453-0 [ebook]

ISBN 978-88-6969-454-7 [print]

Il volume è finanziato peril $40 \%$ dall'Associazione per lo Studio in Italia dell'Asia centrale e del Caucaso (ASIAC) e per il 60\% dal Master in Economia e lingue dell'Europa Orientale dell'Università Ca' Foscari Venezia

Certificazione scientifica delle Opere pubblicate da Edizioni Ca' Foscari - Digital Publishing: tutti i saggi pubblicati hanno ottenuto il parere favorevole da parte di valutatori esperti della materia, attraverso un processo di revisione anonima sotto la responsabilità del Comitato scientifico della collana. La valutazione è stata condotta in aderenza ai criteri scientifici ed editoriali di Edizioni Ca' Foscari.

Scientific certification of the works published by Edizioni Ca' Foscari - Digital Publishing: all essays published in this volume have received a favourable opinion by subject-matter experts, through an anonymous peer review process under the responsibility of the Scientific Committee of the series. The evaluations were conducted in adherence to the scientific and editorial criteria established by Edizioni Ca' Foscari.

Armenia, Caucaso e Asia Centrale. Ricerche 2020 / Carlo Frappi, Paolo Sorbello - 1. ed. - Venezia: Edizioni Ca' Foscari - Digital Publishing, 2020. - 284 p.; 23 cm. - (Eurasiatica; 15). - ISBN 978-88-6969-454-7. 
Armenia, Caucaso e Asia Centrale

Ricerche 2020

a cura di Carlo Frappi e Paolo Sorbello

\section{Sommario}

Introduzione

Carlo Frappi, Paolo Sorbello

Armenians on the Via Francigena. Armenian and Latin Sources on the Origins of the Armenian Community of Orvieto (Urbs Vetus)

Stephanie Pambakian, Lidia Zanetti Domingues

Ti proteggo, ti punisco. L'agire imprevedibile dei santi e degli spiriti osseti

Paolo Ognibene

«Da qualche parte si veglia ancora...». La poesia «Сидзæргæс» di Kosta Chetagurov

Alessio Giordano, Michele Salvatori, Vittorio Springfield Tomelleri 51

La divulgazione orientalista francese di fine Ottocento e lo sviluppo sociale dei popoli d'Oriente: gli Armeni di Ernest Chantre

Massimiliano Vaghi

Armenian Press in Turin. 1915-18

Sona Haroutyunian

The Wilsonian Moment of the Azerbaijani Delegation in Paris (1919-20)

Daniel Pommier

Armenian Clergy and Conflict Management in Lebanon, 1920-1994

Francesco Mazzucotelli

Alcune considerazionisulla situazione attuale della lingua svana

Breve storia degli studie pianificazione linguistica

Alessio Giordano 
The Prospect of the Russian Language in Georgia. Insights from the Educated Youth

Daniele Artoni, Sabrina Longo

Le trasformazioni urbane nella Tbilisi post-sovietica

Note su istituzioni,modernità e spazi della città

Vincenzo Zenobi

The Cultural and Political Claims of the Caucasian Minorities in Turkey

Fabio Grassi

Central Asia in Contemporary Russian Literature Among Nostalgia, Trauma and Orientalism

Dmitry Novokhatskiy

The Role of Kazakhstani Society in the State Development An Overview of the Current Situation, Between Governmental Ficklenessand Nation Branding Initiatives 


\title{
«Da qualche parte si veglia ancora...»». La poesia «Сидзæргæс» di Kosta Chetagurov
}

\author{
Alessio Giordano \\ Scuola Universitaria Superiore IUSS Pavia \\ Michele Salvatori \\ Liceo Scientifico «E. Medi», Montegiorgio; Liceo Scientifico «T. Calzecchi Onesti», Fermo, Italia \\ Vittorio Springfield Tomelleri \\ Università degli Studi di Macerata, Italia
}

\begin{abstract}
Among the poems of Kosta Khetagurov included in the collection Iron Fændyr (Ossetian Lyre), the one entitled "Sidzærgæs" ('Widow', literally 'Mother of Orphans') deserves particular attention. Written probably at the end of the 1880s, the text describes a tragic familiar scene with an unhappy end. The portrait of a young woman, cooking a soup, and her five hungry children, sitting around the hearth and eagerly awaiting the dinner, is one of the most tearful and emotional scenes, well-known and beloved by all Ossetians. The present article presents a multi-layered analysis of the text. The introduction provides relevant biographical and historical information on "Sidzærgæs" and its historical, cultural and literary environment. The Italian literal translation is followed by an interlinear gloss: the first line contains a phonetic-phonological transcription of the text; the second features a semantic and morphosyntactic interpretation of the Ossetic text. In the appendices, beside a cognate poem, written by Kosta in Russian ("V burju"), the reader will find two previously unpublished typescript German translations of "Sidzærgæs”, from the archive of Gappo Baev (Berlin State Library).
\end{abstract}

Keywords Ossetian Poetry. Kosta Khetagurov. Iron Fændyr. Gappo Baev. Mother of Orphans (Widow). Italian and German translation. Lexical and morpho-syntactic gloss.

Sommario 1 Introduzione. - 1.1 La 'riscoperta' di Kosta in epoca sovietica. - 1.2 Kosta e le tradizioni funebri degli osseti. - 1.3 Contenuto della poesia. - 1.4 Una 'parafrasi' in lingua russa. - 2 Edizione. - 2.1 Testo osseto e versione inglese di T.A. Guriev. - 2.2 Traduzione italiana e versione letterale di Dzantiev. - 2.3 Trascrizione fonetica e glossa morfosintattica.

\section{Eurasiatica 15}

e-ISSN 2610-9433 | ISSN 2610-8879

ISBN [ebook] 978-88-6969-453-0 | ISBN [print] 978-88-6969-454-7 


\title{
1 Introduzione
}

Il presente contributo si colloca all'interno del lavoro di traduzione e analisi linguistica dell'opera più importante del poeta osseto Kosta Levanovič Chetagurov (15 ottobre 1859-1² aprile 1906), Iron fœndyr (Lira osseta). ${ }^{1}$ Pubblicata per la prima volta nell'anno 1899 'in contumacia', ovvero quando il poeta si trovava a Cherson a scontare la sua seconda condanna al confino (Bigulaeva 2015, 185-99), ${ }^{2}$ questa raccolta di poesie si apre con un breve componimento, intitolato programmaticamente Nystuan (Testamento), in cui vengono presentati il ruolo e la missione del poeta (Gutiev 1951, 16). Kosta giustifica, scusandosene, il tono triste del suo canto, dovuto principalmente alla consapevolezza dei travagli del popolo osseto e del debito, non ancora estinto, che il poeta sente di aver contratto con i suoi connazionali (Bekoev 1925, 31 = 1982, 34; Tibilov 1936, 9; Gutiev 1951, 6; Salagaeva 1959, 77; Abaev 1961, 72):

\author{
Æ3 дзыллæйæ къаддæр куы дарин, \\ Куы бафидин искуы мæ хæс, \\ Уæд афтæ æнкъардæй нæ зарин, \\ Нæ хъуысид мæ кæуын хъæлæс \\ [...] (cit. in Chetagurov 1999, 14) \\ Se minore fosse il mio debito verso il popolo, \\ Se io potessi prima o poi pagarlo, \\ Non canterei così tristemente, \\ Non si sentirebbe la mia voce piangente. ${ }^{4}$
}

1 Ricordiamo, fra i lavori più recenti, Giordano, Salvatori, Tomelleri 2019; Tomelleri, Giordano 2019 e Tomelleri, Salvatori, Giordano 2020. La versione finale dell'articolo, discussa, rivista e corretta collettivamente, ha visto nella fase preliminare una chiara suddivisione dei compiti: Michele Salvatori ha allestito il testo osseto e le sue diverse traduzioni (§§ 2.1, 2.2 e appendice II), Alessio Giordano ha lavorato alla trascrizione fonetica della poesia (§ 2.3), Vittorio S. Tomelleri ha redatto l'introduzione (§ 1) e curato, oltre alla bibliografia, la glossa morfosintattica (§ 2.3) e la poesia «V burju», edita in appendice I.

2 Kosta non poté nemmeno controllare le bozze del testo mandato in stampa dal curatore, Georgij (Gappo) Vasil'evič Baev (1870-1939), non senza imperdonabili - agli occhi dell'autore - interventi censori e ingerenze lessicali e ortografiche (Epchiev 1951, 25-6; Totoev 1951, 17-18; Gagkaev 1957, 12; Gabaraev 1959, 181-2; Kravčenko 1961, 291-3; Tedety 2009, 326-32); sulle vicende editoriali del testo si veda il recente lavoro di Bigulaeva (2015, 200-30).

3 In Bekoev 1925, 31 la quartina è ovviamente citata in alfabeto latino, introdotto ufficialmente in Ossezia due anni prima: «Ez dzyllæjæ khaddær ku darin, | Ku bafidin isku mæ xæs, | Wæd aftæ ænkhardæj næ zarin, | Næ qusid mæ kæiwynqælæs». Sulla latinizzazione della scrittura osseta si vedano Tomelleri 2016 e 2018b; sulla latinizzazione più in generale nel contesto sovietico si rimanda a Tomelleri 2018a e alla bibliografia ivi citata.

4 Ove non diversamente indicato, tutte le traduzioni sono degli Autori. 
Ritornato in patria dopo la non fortunata esperienza all'Accademia delle Belle Arti di San Pietroburgo (Bigulaeva 2015, 35-40), interrotta per mancanza di sussidi, il poeta si scontra con la situazione di estrema miseria in cui versa il Caucaso, e in particolare l'Ossezia. Già Aleksandr Sergeevič Puškin, nel suo viaggio a Arzrum del 1829, aveva avuto modo di constatare che «gli Osseti sono la tribù più povera fra i popoli che risiedono nel Caucaso» (Puškin 2013, 62). ${ }^{5}$

Con un lessico semplice e senza artifici Kosta riesce a farsi interprete sincero e partecipe delle istanze dei popoli montanari, cantando le sofferenze dei deboli e degli oppressi, non senza ricorrere a riferimenti squisitamente autobiografici. L'importanza della sua opera venne colta immediatamente dai suoi contemporanei. Il giornale Peterburgskie vedomosti del 1906 (n. 69), per esempio, così commentava la prematura scomparsa del poeta:

Весь осетинский народ буквально зачитывался этими поэмами, и отдельные отрывки из них обратились прямо-таки в народные песни, которые можно услышать в любой осетинской деревушке. Имя Коста каждым осетином произносилось буквально с благоговением. В каждой дружеской осетинской пирушке самый главный тост всегда был за поэта Коста, наиболее лучшие стихотворения которого тут же распевались. Таким образом, в лице умершего Коста Хетагурова осетины понесли тяжелую невознаградимую национальную утрату [...]. (cit. in Salagaeva 1959, 147)

Tutto il popolo osseto si è letteralmente immerso nella lettura di queste poesie, e singole parti di esse si sono addirittura trasformate in canti popolari, che è possibile sentire in un qualsiasi paesino osseto. Il nome di Kosta veniva pronunciato da ogni osseto con vera e propria venerazione. Ad ogni banchetto osseto fra amici il brindisi più importante era sempre dedicato al poeta Kosta, del quale per l'occasione venivano recitate le migliori poesie. Pertanto, con la morte di Kosta Chetagurov gli osseti hanno subito una pesante e incolmabile perdita nazionale.

5 «Осетинцы - самое бедное племя из народов, обитающих на Кавказе» (testo russo citato in Abaev 1950, 42; Gabaraev 1959, 204; Chetagurov 1959, 10; Kravčenko 1959, 5).

6 Questa e altre reazioni della carta stampata dell'epoca alla morte del poeta sono raccolte in Chetagurov 1961, 488-93 e in Kravčenko 2008, 89-90. 


\subsection{La 'riscoperta' di Kosta in epoca sovietica}

Nonostante i proclami della propaganda sovietica, che a più riprese ha visto nell'Ottobre Rosso il semaforo 'verde' per l'ingresso ufficiale di Kosta nel pantheon dei poeti nazionali, con conseguente restituzione al popolo della sua eredità (Avruščenko 1940, 100; Chadarceva 1956, 22), è il 1939 la data che ne sancì il riconoscimento ufficiale da parte delle autorità, suggellando per così dire il trionfo della politica nazionale di Lenin e Stalin (Kulov 1939, 11; Chetagurov 1959, 44). Al 21 luglio di quell'anno, infatti, risale il decreto del Consiglio dei commissari del popolo e del Comitato centrale del Partito comunista, in occasione dell'ottantesimo anniversario della nascita del poeta, che sottolinea la straordinaria importanza politico-culturale della sua opera e i suoi meriti di attivista sociale (Korzun 1954, 55). Il testo, che porta la firma di Vjačeslav Michajlovič Molotov e di Iosif Vissarionovič Stalin, inizia così:

Постановление Совета Народных Комиссаров Союза ССР и Центрального Комитета ВКП(б) о проведении 80-летнего юбилея со дня рождения народного осетинского поэта и общественного деятеля Константина Левановича Хетагурова. (Jubilej 1941, 5-6) ${ }^{7}$

Decreto del Consiglio dei commissari del popolo dell'Unione delle Repubbliche Socialiste Sovietiche e del Comitato centrale del Partito comunista panunionista (bolscevico) sulla celebrazione dell'ottantesimo anniversario della nascita del poeta popolare e attivista osseto Kosta Levanovič Chetagurov.

In quell'occasione, fra le altre cose, si decise di ribattezzare Georgievsko-Osetinskoe, situato sulla riva sinistra del fiume Kuban, ${ }^{\prime}{ }^{8}$ in Selo imeni Kosta Chetagurova, denominazione che questa località, facente parte oggi della Repubblica di Caraciai-Circassia (Federazione Russa), conserva tutt'ora. Nello stesso anno anche il giornale Pravda, in un editoriale dedicato a Kosta, scriveva:

Каждый народ рождал героев, поднимавших людей на бой против рабства, за свободу и счастье..Таким героем для

7 Il testo del decreto, che si può leggere in un volume celebrativo dedicato a Kosta (Jubilej 1941), è ora disponibile anche in rete: https://oldvladikavkaz.livejournal. com/195331.html.

8 Lo aveva 'fondato' nel 1868 il padre del poeta, Levan Elizbarovič Chetagurov, popolandolo con una comunità di coloni osseti senza terra provenienti dalla gola di Nar (Gutiev 1951, 7). 
осетинского народа являлся Константин Леванович Хетагуров. (cit. in Abaev 1961, 182)

Ogni popolo ha dato alla luce eroi che hanno spronato la gente a combattere contro la servitù, per la libertà e la felicità... questo eroe, per il popolo osseto, è stato Konstantin Levanovič Chetagurov.

Il 1939, infine, registra anche la prima traduzione russa di Iron feendyr (Chetagurov 1939), peraltro giudicata non del tutto soddisfacente (Kulov 1947, 11).

Prima di questa canonizzazione ufficiale, che fece di lui un antesignano del comunismo rivoluzionario (Fadeev 1941, $3=2009$, 26), non erano peraltro mancate, anche in organi autorevoli, voci critiche e perfino accuse di nazionalismo nei confronti di Kosta. Per esempio, nel quinto volume dell'enciclopedia letteraria, alla voce «Kosta» leggiamo le seguenti considerazioni tutt'altro che lusinghiere:

Но поэт-народник не видит, не умеет найти ясного исхода; отсюда - хотя K. для своей эпохи безусловно поэт революционный (в смысле национального освобождения) - националистические и даже мистические нотки в его творчестве. Это - результат известного раздвоения, неустойчивости социального бытия К. Отсюда и воспевание православия, внедрившегося в Осетию вместе с торговым капиталом, отсюда мистицизм и частые отступления от своих же идеалов. Творчество К. в наше время используется реакционными слоями национальной интеллигенции в своих интересах; ударение при этом делается на националистических мотивах поэзии К. (Abaev, Farneev 1931, 506)

Ma il poeta-democratico non vede, non è in grado di trovare una chiara via d'uscita; questo spiega perché, sebbene K. per la sua epoca sia certamente un poeta rivoluzionario (nel senso di liberazione nazionale), si riscontrano nella sua opera note nazionalistiche e persino mistiche. Questa è la conseguenza di un certo dualismo, di una certa instabilità della natura sociale di K. Di qui anche la glorificazione dell'ortodossia, penetrata in Ossezia insieme al capitale mercantile, di qui il misticismo e le frequenti deviazioni dai propri ideali. L'opera di K. viene oggi utilizzata a proprio vantaggio dai gruppi reazionari dell'intelligencija nazionale, i quali nel far questo sottolineano i motivi nazionalisti della poesia di K. 


\subsection{Kosta e le tradizioni funebri degli osseti}

La poesia qui presa in esame, intitolata «Sidzærgæs», ovvero 'La vedova', ${ }^{\prime}$ è ritenuta a buon diritto una perla della produzione poetica di Kosta (Abaev 1950, 39). Caratterizzata da elevatissimo impegno sociale e intensità emotiva (Kulov 1947, 13), essa, come tanti altri componimenti della raccolta Iron foendyr, è stata molto probabilmente composta durante il periodo trascorso da Kosta a Vladikavkaz (188591), considerato il più prolifico in relazione alla produzione del poeta in lingua osseta (Abaev 1939, 153; ${ }^{10}$ Epchiev 1951, 11).

Si tratta inoltre della prima poesia osseta di Kosta tradotta in russo prima della Rivoluzione d'Ottobre (Chadarceva 1956, 21). Pochi anni dopo l'uscita della raccolta, infatti, più precisamente nell'estate del 1902, lo scrittore e pubblicista georgiano Levan Qipiani (18631936) inviò da Tbilisi all'autore e amico la propria traduzione russa della poesia: ${ }^{11}$

Коста! Посылаю тебе [мой] перевод твоего чудного «Сидзæргæс»- появилось ${ }^{12}$ в «Кавказском вестнике» [n. 7]. (Tedety 2009, 335) ${ }^{13}$

Kosta. Ti mando la [mia] traduzione del tuo meraviglioso «Sidzærgæs» - è uscita su Kavkazskij vestnik [n. 7].

Il paesaggio montano e l'ambientazione invernale fungono da cornice per una vicenda nella quale una figura priva di tratti persona-

9 In realtà si tratta di un composto, il cui primo elemento è il sostantivo sidzœr, che significa orfano, e il secondo un deverbativo tratto dalla radice del verbo kœsyn (guardare, accudire), con regolare sonorizzazione della consonante iniziale nel secondo membro del composto (Gagkaev 1957, 88; Abaev 1964, 110); lo stesso Kosta aveva annotato su un quaderno alcuni esempi di formazione delle parole in cui detto fenomeno si verifica (Salagaeva 1959, 137). La traduzione letterale è pertanto 'madre degli orfani' (cf. Guriev 2015, 217).

10 Il testo di questo articolo, rilevante per la collocazione editoriale, per il nome del suo autore ma, soprattutto, per la data di pubblicazione (cf. supra), è stato ripubblicato alcuni anni più tardi come parte iniziale di un nuovo contributo (Abaev 1960, 72-6), riproposto in forma molto ridotta, e senza questa parte, nel primo volume dell'Opera selecta (Abaev 1990, 552-4). In Abaev 1939 l'intervallo temporale indicato è 1884-90, qui corretto sulla base di altre fonti (Gutiev 1951, 10; Korzun 1954, 65; Gabaraev 1959, 31).

11 Il testo, che porta il titolo Mat' (Madre), è stato ristampato da Dzasochov (1909, 130-2); il frontespizio di questo libro è riprodotto nel secondo volume dell'Opera omnia di Kosta (Chetagurov 1951a, 48-9).

12 In Korzun (1952, 120, nota 1), che riporta il passo, si legge invece «появится», 'uscirà'.

$13 \mathrm{Si}$ veda anche http://nslib.tmweb.ru/tvorchestvo/kosta/perepiska/1. php? value=14. 
li diviene simbolo della disperata lotta di una povera vedova in difesa dei propri figli contro un nemico implacabile come la fame. La descrizione, che non rinuncia a dettagli molto realistici e crudi, culmina nella propria drammaticità alla penultima strofa, quando il lettore scopre la triste verità (Korzun 1957, 144); in modo sobrio e sintetico viene dipinto un quadro toccante e indimenticabile della vita grama dei montanari ${ }^{14}$ e dell'amore materno. Kosta mette in bocca alla vedova infelice una formula tipica di lamento, che consiste nel rivolgersi al defunto con parole di biasimo (Salagaeva 1959, 104), secondo una pratica che lo stesso poeta aveva descritto nel suo trattato etnografico Osoba, ora disponibile anche in traduzione francese integrale (Khétagourov 2005):

Оплакивая покойника, к нему иногда обращаются с проклятием, - судзгæ фæбадай (сидеть тебе в огне), - за то, что он покинул малолетних детей, оставил несчастных стариков без потомства и т. д. (Chetagurov 2012, 50)

Quando si piange un defunto, a volte lo si maledice dicendo sudzgoe foebadaj (resta a bruciare nel fuoco), per aver abbandonato i figli ancora piccoli, aver lasciato dei vecchi infelici senza discendenza ecc.

L'interesse per i riti funebri del popolo osseto, particolarmente sontuosi e solenni per la credenza che la vita nell'aldilà fosse la continuazione della vita terrena (Malinkin 1941, 35-6), marca anche l'inizio dell'attività pubblicistica di Kosta. Questi aveva manifestato la sua vocazione etnografica in un articolo uscito sul giornale Severnyj Kavkaz del 1887 (n. 44), dal titolo «Pominki u osetin» (I funerali presso gli Osseti) (Korzun 1957, 43). Nelle Vladikavkazskie pis'ma (Lettere da Vladikavkaz), pubblicate sul giornale Severnyj Kavkaz (n. 36 del 1896), Kosta sottolineava la necessità di superare le credenze sull'oltretomba e le superstizioni del popolo osseto:

А пока осетин глубоко верит, что каждый покойник на том свете нуждается в пище и питье и что священная обязанность родственников покойного - доставлять им эти предметы потребления в установленном порядке и количестве, до тех пор невозможно сознательное уничтожение в народе «суеверных и разорительных» поминок. (Chetagurov 1951b, 17)

14 Kosta è stato per l'appunto definito «cantore della miseria dei montanari osseti» (Gadiev 1926).

15 Cf. anche Salagaeva 1959, 104-5. 
Finché gli osseti continueranno a credere fermamente che ogni defunto nell'aldilà ha bisogno di cibo e bevande e che è dovere sacrosanto dei parenti del defunto procurargli questi beni nel modo e nella quantità stabiliti, non sarà possibile sradicare dal popolo in modo consapevole i riti funebri 'superstiziosi e rovinosi'.

La morte del pater familias significava in genere, per una famiglia, il tracollo economico (Tuaev 1941, 212); anche l'organizzazione in grande stile del rito funebre condannava spesso alla rovina le famiglie meno abbienti, come registrava la ricerca etnografica ancora negli anni Venti del secolo scorso (Čursin 1925, 89).

Il poeta impiega il lamento funebre come espediente per dipingere a tinte vivide la miseria del popolo osseto; proprio la donna svolgeva un ruolo di primo piano nelle situazioni di lutto:

До дня похорон покойник оставался на скамье в хадзаре: его окружали исключительно женщины. (Chetagurov 2012, 50)

Fino al giorno delle esequie il corpo del defunto rimaneva nella casa su una panca: gli stavano intorno soltanto donne.

\subsection{Contenuto della poesia}

Protagonista del dramma familiare è una giovane madre, rimasta vedova, la quale, trattenendo a stento il dolore, cerca di far addormentare i propri figli piccoli. Alla richiesta di uno di loro, che vuole mangiare, ella risponde, senza riuscire a trattenere le lacrime, che la cena è quasi pronta e che ci sarà da mangiare per tutti, ma in realtà sta disperatamente mentendo. A poco a poco, spossati, i piccoli si addormentano uno dopo l'altro, e alla fine viene svelato l'arcano mistero della lunga cottura: la pentola non conteneva fagioli, ma pietre, messe a cuocere per tranquillizzare i figli affamati (Ivanov 1941, 123-4 = 1989, 137-9; Korzun 1957, 141-4; Salagaeva 1959, 103-4). La madre, ingannati i cinque orfanelli, piange tutta la notte, aspettando con terrore il mattino seguente, quando i bambini si sveglieranno e si metteranno di nuovo a chiedere da mangiare (Abaev 1961, 21).

L'opera richiama il poemetto Moroz, Krasnyj nos (Gelo, naso rosso) di Nikolaj Alekseevič Nekrasov (1821-1878), composto nel 1863 e dedicato alla sorella Anna Alekseevna. Sono stati proposti anche altri possibili modelli che avrebbero ispirato Kosta, fra cui andrebbero menzionati il poema dello scrittore austriaco Moritz Hartmann 
(1821-1872), Der weisse Schleier ${ }^{16}$ (Il velo bianco) e la poesia di Ivan Savvič Nikitin (1824-1861), Žena jamščika (La moglie del cocchiere) ${ }^{17}$ (Berkov 1969; cf. anche Chetagurov 1999, 456); altri ritengono invece che si debbano prendere in maggiore considerazione motivi orientali, come la fiaba turca del califfo Yemer (Nesin 1979) o anche scenari analoghi della tradizione caucasica daghestana (Kodzati 1999). Interessanti e stimolanti, anche in relazione alla presenza del motivo nelle letterature europee, sono le considerazioni di Dziccojty (2017), il quale ritiene non realistica la condizione di totale solitudine e abbandono in cui versa la donna: per la società osseta del tempo, infatti, l'occorrenza concomitante della situazione descritta - una giovane vedova abbandonata al proprio destino, senza il supporto della famiglia, di lei o del marito defunto, e per di più nel totale disinteresse dei compaesani - costituisce un fatto storicamente inverosimile. Berkov (1969) ha proposto infine un'ardita ma suggestiva interpretazione di «Sidzærgæs» in chiave metaforica e autocritica: Kosta avrebbe voluto rappresentare come bambini affamati il popolo osseto in attesa del proprio nutrimento spirituale, ovvero testi in lingua osseta, mentre il poeta, invece di cucinare loro un pasto delizioso, li cullava con illusorie promesse scrivendo in russo.

La poesia ebbe subito un notevole impatto sul popolo. Come riferisce il giornale Terskie vedomosti del 1890 (n. 25), Kosta l'avrebbe recitata il 18 marzo 1890 in occasione di una serata artistico-letteraria di beneficenza, producendo nei presenti una profonda impressione (Epchiev 1951, 36; Korzun 1957, 141, nota 1). Anche lo scrittore osseto Baron Timofeevič Bociev (1901-1944) ricordava l'entusiasmo provocato nella sua famiglia dall'ascolto del testo:

Я помню, когда мой дядя, который был грамотным человеком, принес домой «Ирон фæндыр» и стал читать, то все домашние, а особенно женщины, заплакали, услышав «Мать сирот». Это было так всем знакомо, что никто не мог оставаться равнодушным. Когда я спросил: - А кто такой Коста? Мне ответили: - Это защитник бедняков. Потом я стал сам слагать о нем песни и стихи. (Bociev 1941, 164)

Mi ricordo che quando mio zio, che era una persona di cultura, portò a casa Iron fœendyr e cominciò a leggere, tutti a casa, in particolare le donne, si misero a piangere dopo aver sentito la poesia «La madre degli orfani». Questo testo era talmente noto a tutti che

16 Incipit: «Im Kerker liegt in eisernen Banden | beim Henkermahle der Ungargraf» (Hartmann 1874, 140-3).

17 Incipit: «Жгуч мороз трескучий, | на дворе темно» (Nikitin 1915, 20-26).

18 Cf. anche Salagaeva 1959, 144. 
nessuno poteva rimanere indifferente. Quando io chiesi - Ma chi è Kosta? Mi riposero: 'Il difensore dei poveri'. Dopodiché mi sono messo io stesso a comporre canti e versi su di lui.

\subsection{Una 'parafrasi' in lingua russa}

Analogo tema è stato sviluppato dal poeta nella poesia «V burju» (Durante la tempesta), composta in lingua russa (Malinkin 1941, 25), presumibilmente nel 1889 (Chetagurov 1951a, 350) e qui pubblicata nella prima appendice con una traduzione letterale a fronte (cf. appendice I). La versione russa può essere considerata una sorta di riassunto o parafrasi del testo osseto; lo sviluppo della medesima trama in due lingue dimostra che il poeta voleva garantire maggiore diffusione possibile al tema del dramma femminile e materno (Semënov 1951, 11-12). Kosta fu infatti sempre sensibile al ruolo fondamentale, ma subordinato, della donna nella società caucasica e al suo - il più delle volte triste - destino (Salagaeva 1959, 7; Apresjan 1962, 10 11); emblematiche sono le sue amare parole nella poesia «Na smert' gorjanki» (Per la morte di una montanara): ${ }^{19}$

Ничего, что она молода!..

Кроме рабства, борьбы и труда,

Ни минуты отрадной свободы

Ей бы жизнь не дала никогда,

Хорошо умереть в ее годы.

(Chetagurov 1951a, 16)

Non importa che fosse giovane!..

Altro che schiavitù, lotta e fatica,

Nemmeno un momento di gioiosa libertà

La vita non le avrebbe mai concesso,

È un bene che sia morta alla sua età.

Oltre a ciò, il poeta, privato molto presto del calore materno, provò sempre un sentimento di particolare affetto verso i bambini (Abaev 1961, 48), come attestano i primi versi della poesia «Tæxudy» (Desiderio) (Bigulaeva 2015, 21; Giordano, Salvatori, Tomelleri 2019, 273); ai bambini sono dedicate alcune delle sue migliori poesie (Avruščenko

19 Sul giornale Severnyj Kavkaz (n. 30 del 1889), dove la poesia fu pubblicata per la prima volta, nel titolo il sostantivo gorjanki era preceduto dall'aggettivo molodoj, 'giovane' (Chetagurov 1951a, 349-50). 
$1940,108) .{ }^{20} \mathrm{Il}$ carattere socialmente impegnato di questo componimento, inoltre, ne ha fatto oggetto di attenzione musicale, con la creazione di melodie popolari che ne accompagnavano l'esecuzione (Salagaeva 1959, 139).

\section{Edizione}

Il componimento osseto, che comincia con la cupa ambientazione montana di una tempesta di neve, per passare poi alla descrizione di una scena familiare attorno al focolare acceso, rivela la predilezione del poeta per l'asindeto, costrutto sintattico che caratterizza il registro colloquiale, conferendo al dettato del testo una maggiore intimità. L'uso di frasi coordinate semplici e brevi (Salagaeva 1959, 135), inoltre, permette di attirare l'attenzione del lettore su singoli particolari, mentre il legame logico-sintattico fra gli eventi viene intuito sulla base del contenuto dell'opera (Gagkaev 1957, 118); ${ }^{21}$ in questo caso, peraltro, l'intento di Kosta non è tanto descrivere una sequenza di eventi narrativi, quanto concentrare la propria ispirazione poetica sulla rappresentazione dello stato emotivo di una giovane donna rimasta sola dopo la tragica morte del coniuge (Dziccojty 2017).

Pubblichiamo qui sotto il testo di «Sidzærgæs» secondo l'abituale struttura a più strati: al § 2.1 viene riportato l'originale osseto, in ortografia corrente, preceduto dal facsimile del manoscritto autografo (Chetagurov 2009) e affiancato dalla traduzione letterale inglese ad opera del compianto Tamerlan Aleksandrovič Guriev (2009); segue, al $\S 2.2$, la resa in lingua italiana, cui si aggiunge anche il podstročnik di Anatolij Aleksandrovič Dzantiev (2009). La trascrizione fonetica, con glossa lessicale e morfosintattica, intende infine offrire un valido strumento di analisi linguistica (§ 2.3). L'edizione è inoltre arricchita da due appendici: la prima presenta il testo della poesia di Kosta «V burju» con una traduzione italiana il più possibile letterale (appendice I); la seconda, invece, contiene una duplice traduzione tedesca, finora inedita, tratta dall'archivio personale di Gappo Baev (appendice II).

20 Avruščenko riporta anche, in traduzione russa, un verso della poesia in cui il bambino stanco e affamato viene così descritto: «Уснул у очага самый лучший из людей» (si è addormentato vicino al focolare il migliore di tutti).

21 A pagina 119 lo studioso riporta, fra gli altri, proprio l'incipit di «Sidzærgæs»; la pregevole monografia di Gagkaev (1957), unica nel suo genere, va letta tenendo presenti alcune critiche sostanziali di Tokazov 1959. 
auor saprobcin errestul..

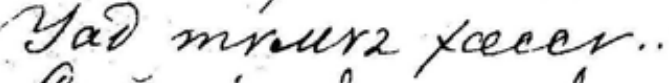

Cay ajuceder prustor

Hapr gey yicer..

Dapr a ceceb priñorap.

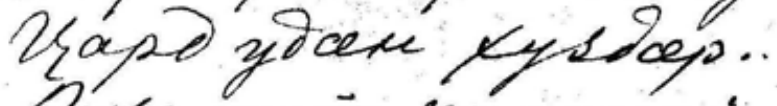

Dipe uneyt kajareaj; -

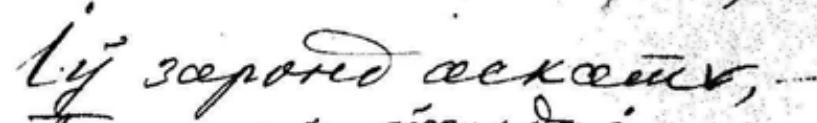

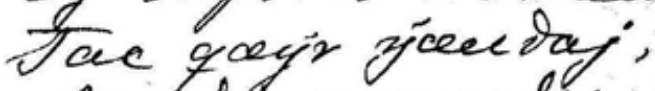

Assade groegrad,

Ays dceutryaji-

Figura 1 Chetagurov 2009, 56 
Alessio Giordano, Michele Salvatori, Vittorio Springfield Tomelleri «Da qualche parte si veglia ancora...». La poesia «Сидзæргæс» di Kosta Chetagurov

Ha tisxa jo tabüre:Yyajpaty youque Ap exin joe apuime ky eayoaper ye.

Apnìscecuer zcopseñeñs, Apcernuna arrace.

badrur evbancicentūer, ri ocorros, ri sun...

Yasan ance correzaj. bipan-Deep ninceper.Hececer cebburey oryenuñ Yocer...

- Lla кaym, иo Кирū́ce, Asypr can ca cuad, Apryaj quedynum. Atraym crunad...

Aliñajobar opecens

llapr gicencerce Hacuererz casrceils Arunce cyearcy:

Figura 2 Chetagurov 2009, 58

Eurasiatica $15 \mid \mathbf{6 3}$

Armenia, Caucaso e Asia Centrale. Ricerche 2020, 51-90 
Dipfunce cpedsce qapon:

"Dybre quevada

"Baje orve rice dapcer. "Nay ri quecajdba...

"Qporcisel yje reryasdda

"L revjaparcen,-

"Cllatr zoppo criaxinda.

"Yapcebuivo quoveere!.

"Buredaj ure quceürydee,

"O. une nceotr Yaj,-

"Gidsepuñoj quouradoce

"Lricernuce ñopraj!!

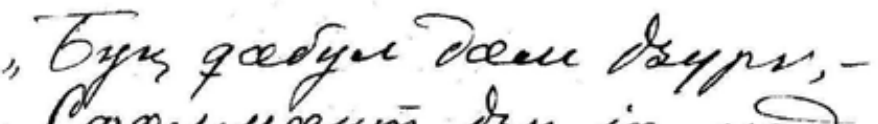

"Copanuceum us joe nad..

"Mapcer-Dop doe sypr

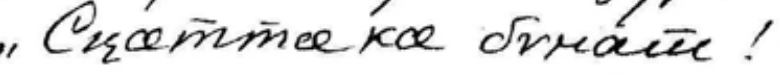

Yyocinvar ceszous

Aruce cycorco:

Niniajotar cejeceen

- llapr gsoisceraj:. 
Alessio Giordano, Michele Salvatori, Vittorio Springfield Tomelleri

«Da qualche parte si veglia ancora...». La poesia «Сидзæргæc» di Kosta Chetagurov

baquencua kecyroy

tirurum xacoap,-

karcajer apprreef;

ofocur Yyzocep:-

Lijn-Dop tee advec Auyusiscer, quarcey.'

Corper cerce qucelicabru thive tycecer xan recoy!.

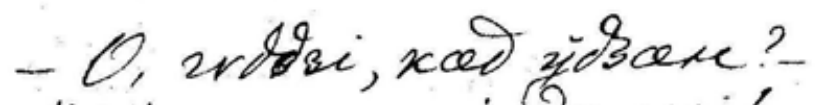

paje-na raj da ar..

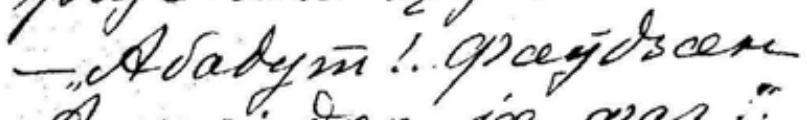
Anxcej-oxp joe gras."

A2 kener jee oreineag; -

"Qcedypince" govirvey.

Aurpar insuceóranca.

Cilsepiño yjcerrey..

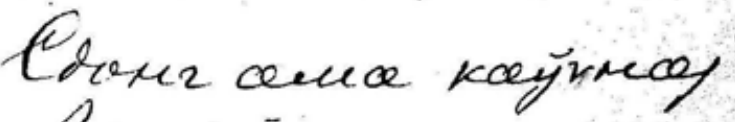
llor $x y$ equanucenś, thapos y jaid jice gorreg; Macū cen rear qyer.

Figura 4 Chetagurov 2009, 62

Armenia, Caucaso e Asia Centrale. Ricerche 2020, 51-90 
Orciñur ux co yacǘda llar ja queryeur, Adaperce ca rexpsinda Aun orzaypins..

Cxodda ca pcetrucy: haj-La-ha:'Kayirucej

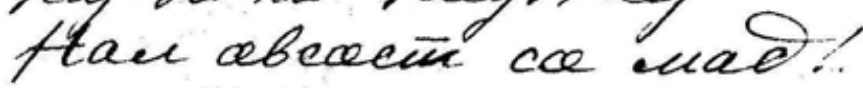

Oidscepuncere qoetypunce Cejcobas Yydta, Aqūnceuce evre dypunce vyajicader gorkmba,Agorevre abcorer bajporya ca KapD... coarer cenajo rece zoreriy cajol ru cesaced. 


\subsection{Testo osseto e versione inglese di T.A. Guriev}

\section{Сидзæргæс}

Халон баргъæвст сындзыл... Уад тымыгъ хæссы... Сау айнæджы рындзыл Нарыхъæу хуыссы...

Даргъ æхсæв фыдбонæй Цард удæн - хуыздæр... Рухс цæуы кæронæй, Бадынц ма кæмдæр...

Иу зæронд æскъæты, Гас хъæуы уæлдай, Аззади фæсвæды ${ }^{1}$ Ацы бæстыхай, -

Ма дис кæн ${ }^{2}$ йæ бадтыл! Цуайнаджы уæлхъус Архайы йæ артыл Иу саударæг ус.

Артдзæсты кæрæтты, Фæныкмæ æнгом Бадынц сывæллæттæ, чи бæгънæг, чи гом...

Уазал æмæ стонгæй Бирæгъ дæр тæрсы, Удхæссæг æввонгæй Ахæмты хæссы...

- Ма кæут, мæ хуртæ, Дзуры сæм сæ мад, Афыцой хъæдуртæ... Абадут æнцад!..

Митæйдзаг æхсæлы Мары фæздæгæй... Цæстысыг æзгъæлы Агмæ сусæгæй...

Хурхмæ схæццæ ${ }^{3}$ хъарæг: «Дудгæ фæбада Зæйы бын нæ дарæг, Мах чи фæсайдта!..

Фондзæй уæ ныууагъта Иу ныййарæгæн, Мады зæрдæ скъахта, Царæфтыд фæдæн!..

\section{Widow}

A raven is frozen on a sloe... Snow-storm is awful. On the edge of a rock Nar-aul is sleeping...

A long night is better Than a painful day... There is light somewhere, Someone isn't sleeping yet.

In one cattle-shed On the edge of the aul This house Is quite lonely...

You must not be surprised At this late sitting!.. A widow in black Is busy at (over) cauldron.

Round the fire Close to the ashes Children are sitting, Some in rags, some naked...

Even a wolf is afraid Of cold and hunger. Death willingly Takes such poor.

- You don't cry, my darlings, Their mother is saying, -

Sit still for a while, We'll have beans for supper!

The smoke of juniper Is biting the eyes. The tears are falling Into the cauldron.

She starts her lamentation. "Let our broad-winner [sic] Suffer under the avalanche, The one who deceived us!..

Five of you he left To the care of mother, And now this burden Is tearing my heart to pieces!.. 
Зондæй мыл фæтых дæ,

О, мæ лæджы хай, -

Сидзæртæй фæлыгътæ

Ингæнмæ тæргай!..

Буц хъæбул дæм дзуры, Сфæлмæст ${ }^{4}$ дзы йæ мад, Махæн дæр дæ цуры

Сцæттæ кæ бынат!»

Цæстысыг æзгъæлы Агмæ сусæгæй...

Митæйдзаг æхсæлы

Мары фæздæгæй...

Бафæллад кæуынæй Бинонты кæстæр, Къонайыл æрфынæй Адæмы хуыздæр! -

Иууылдæр дæ адыл Тулдзысты, фæлæу! Стонг æмæ фæлладыл Тых хуыссæг кæм нæу!..

- О гыцци кæд уыдзæн? Райс-ма, цæй, дæ аг!.. - Абадут!..Фæуыдзæн Алкæй дæр йæ фаг...

Аг кæлы йæ былтæй, «Хъæдуртæ» фыцынц... Алы ран тымбылтæй Сидзæртæ хуыссынц...

Стонг æмæ кæуынæй Лæг куы сфæлмæцы, Тарф у уæд йæ фынæй, Маст æм нал хъуысы.

Лыстæнмæ сæ хаста Мад йæхъæбулты, Адæрсгæ сæ нуæрста Алы бызгъуырты...

Скодта сæ рæбынæй, Дæлфæдтæм æрбадт... Гъай-да-гъа! Кæуынæй Нал æфсæст сæ мад!..
You turned out a clever man, Oh, my husband, You ran to your grave From five orphans!..

Your loving baby is calling you, His mother can't stand it any longer You better make a room for us By your side!"

The tears of mother Are dipping into the cauldron... The smoke of juniper Is biting the eyes.

The youngest of the family Is tired of weeping, And the best of the people Has fallen asleep at a hearth.

Now the rest

Will fall asleep, Hunger and fatigue Will overcome.

- Oh, ma, isn't it time? Will you take the cauldron down! - Sit for a while!..

Everyone will have enough.

The cauldron is full, 'The beans' will soon be ready... The orphans are sleeping Here and there.

When one is tired Of hunger and weeping, His sleep is sound, He'll not feel bitterness.

Mother took her children To their 'bed' - the straw. And carefully covered them With sundry rags.

Now she is sitting At her little dears... And ... She couldn't stop Her weeping. 
Сидзæртæн хъæдуртæ

Се 'хсæвæр хуыдта, Афтæмæй сын дуртæ Цуайнаджы фыхта:

Афыцын æфсоны Байрох уа сæ хæрд... Стонг æмгъуыд нæ зоны,Иу сайд ын æгъгъæд!..

(Chetagurov 1999, 64-71)
She promised the orphans

To give them beans for supper.

But ... there were only stones

In the cauldron:

Waiting they'd forget

Their hunger (supper, meal)...

But hunger doesn't acknowledge postponement

Next time it won't be deceived...

(Guriev 2009, 25-7)

1 Nel manoscritto autografo фæсфæды.

2 Nel manoscritto autografo дис-кæ.

3 Nel manoscritto autografo схæддзæ. Nell'editio princeps di Iron fændyr (1899) il testo recita: «Хъуырмæ [in gola] схæццæ» (Chetagurov 1999, 305).

4 Nel manoscritto autografo сфæлмæцит.

5 Nell'editio princeps di Iron fændyr (1899) il testo recita: «Иууылдæр дæ фæдыл» (Chetagurov 1999, 305).

6 Nel manoscritto autografo гуддзі.

\subsection{Traduzione italiana e versione letterale di Dzantiev}

\section{La vedova}

Il corvo sul prugnolo sente freddo... la tormenta porta una tempesta di neve.. sulla sporgenza di una roccia nera riposa il villaggio di Nar...

Per un'anima viva una lunga notte è meglio del brutto tempo... dalla periferia arriva della luce, da qualche parte si veglia ancora...

In una vecchia stalla, -

all'estremità del villaggio,

è rimasta del tutto isolata

questa abitazione, -

Non meravigliarti di questa veglia! intorno alla pentola

armeggia sul fuoco

una donna vestita a lutto.

Alle estremità del focolare

vicino alla cenere

siedono dei bambini, -

chi nudo, chi vestito di stracci...

\section{Сидзæргæс - мать сирот}

Ворон озяб на колючем кустарнике...

Буря несет метель...

На черной скале, над пропастью,

Спит аул Нар...

Долгая ночь для живой души

Лучше мрачного дня...

Где-то на окраине виден огонек

- Там еще не спят...

В одном старом хлеву, -

На самом краю аула,

На отшибе осталось

Это жилище, -

Не удивляйся, что здесь бодрствуют! Над котелком

Возится у очага

Вдова в траурном одеянии.

Вокруг очага

Рядышком с золой

Сидят дети. -

Кто в лохмотьях, кто гол... 
Del freddo e della fame anche il lupo ha paura, l'angelo della morte prontamente porta via simili persone...

Non piangete, miei soli, - dice loro la madre, i fagioli si devono cuocere... state tranquilli!..

Il ginepro coperto di neve punge (gli occhi) con il fumo... una lacrima finisce furtivamente nella pentola...

In gola si è mescolato il canto: «Se ne stia a soffrire sotto la lavina il nostro capofamiglia che ci ha ingannato!.

In cinque vi ha lasciato a me sola genitrice, della madre il cuore ha lacerato, ora sono rovinata!..

Mi hai superato quanto a sapere, oh, mio caro marito ${ }^{1}$, sei scappato dagli orfani nella tomba, con nostro scorno!..

Il tenero bimbo ti chiama, sua madre è spossata... Prepara anche a noi una dimora vicino a te!»

Una lacrima finisce furtivamente nella pentola... il ginepro coperto di neve punge (gli occhi) con il fumo...

Si è stancato di piangere il più piccolo della famiglia, presso il focolare si addormenta, il migliore di tutti.

Ognuno crollerà come te, fermati! Affamato e stanco come non lo supererà il sonno!..

\section{Холода и голода}

Боится даже волк, -

Костлявая подобных

Уносит без труда...

- Не плачьте, мои солнышки, -

- Говорит им мать, -

Сварится фасоль...

Посидите тихо!..

\section{Заснеженный можжевельник}

Дымом ест глаза...

Слезы (матери) катятся

Украдкой в котелок...

Рыданья душат горло:

«Да постигнут муки

Нашего кормильца, накрытого обвалом, Того, кто обманул нас!..

Пятерых оставил он Мне одной, Истерзал (исковеркал) сердце матери, Разрушен мой очаг!..

Умом ты меня одолел, О, моя мужнина доля, От сирот сбежал ты В могилу, в обиде на нас!..

Любимое чадо зовет тебя, Измучил он свою мать... И для нас рядом с собой Приготовь местечко!»

Слезы скатываются

Украдкой в котелок...

Заснеженный можжевельник

Дымом ест глаза...

\section{Утомился от плача}

Младший из семьи, У очага засыпает тихо, Лучший из людей.

Подобно тебе, и все остальные Вскоре повалятся спать, погоди! Голодного и усталого Не одолеет ли сон!.. 
Oh, mamma, quando è pronto? su, tira fuori il tuo pentolone!.. - State seduti! Ce ne sarà a sufficienza per tutti...

Il pentolone ribolle ai lati, 'i fagioli' cuociono...

Rannicchiati in vari posti gli orfani dormono...

Quando si è sopraffatti dal sonno e dal pianto, allora il sonno è profondo, non si prova più dolore.

La madre ha coricato i piccoli sulla paglia, con premura li ha coperti di vari stracci...

Li ha messi in un angolo, si è seduta ai loro piedi... Deh! Del pianto non si è potuta saziare la madre.

Agli orfani fagioli aveva promesso per cena, ma per loro pietre nel pentolone cuoceva;

Con la scusa del cuocere che dimentichino la fame... la fame non conosce termini, un inganno gli basta.
- О, гыцци, когда же...

Ну, сними свой котелок!

- Подождите, достанется

Вдоволь каждому...

Котелок закипает через край, Варится «фасоль»...

То там, то здесь, свернувшись, Сиротыспят...

Когда с голоду и от плача Утомится человек, Тогда сон у него глубок,Горе он уже не замечает.

Мать укладывала

Своих детей на солому, Заботливо укрывала их

Разными лохмотьями...

Уложив в углу,

Присела у их ног...

И ну, давай! Рыданьем

Не могла уж насытиться мать.

Сиротам она говорила, Что варит кужину фасоль, А сама в котелке Варила для них камни;

Чтобы убаюканные надеждой, Они забыли о голоде... Голодный не знает срока, Для него и простого обмана достаточно!.. (Dzantiev 2009, 314-17)

1 Letteralmente 'mia parte di marito'. 


\subsection{Trascrizione fonetica e glossa morfosintattica}

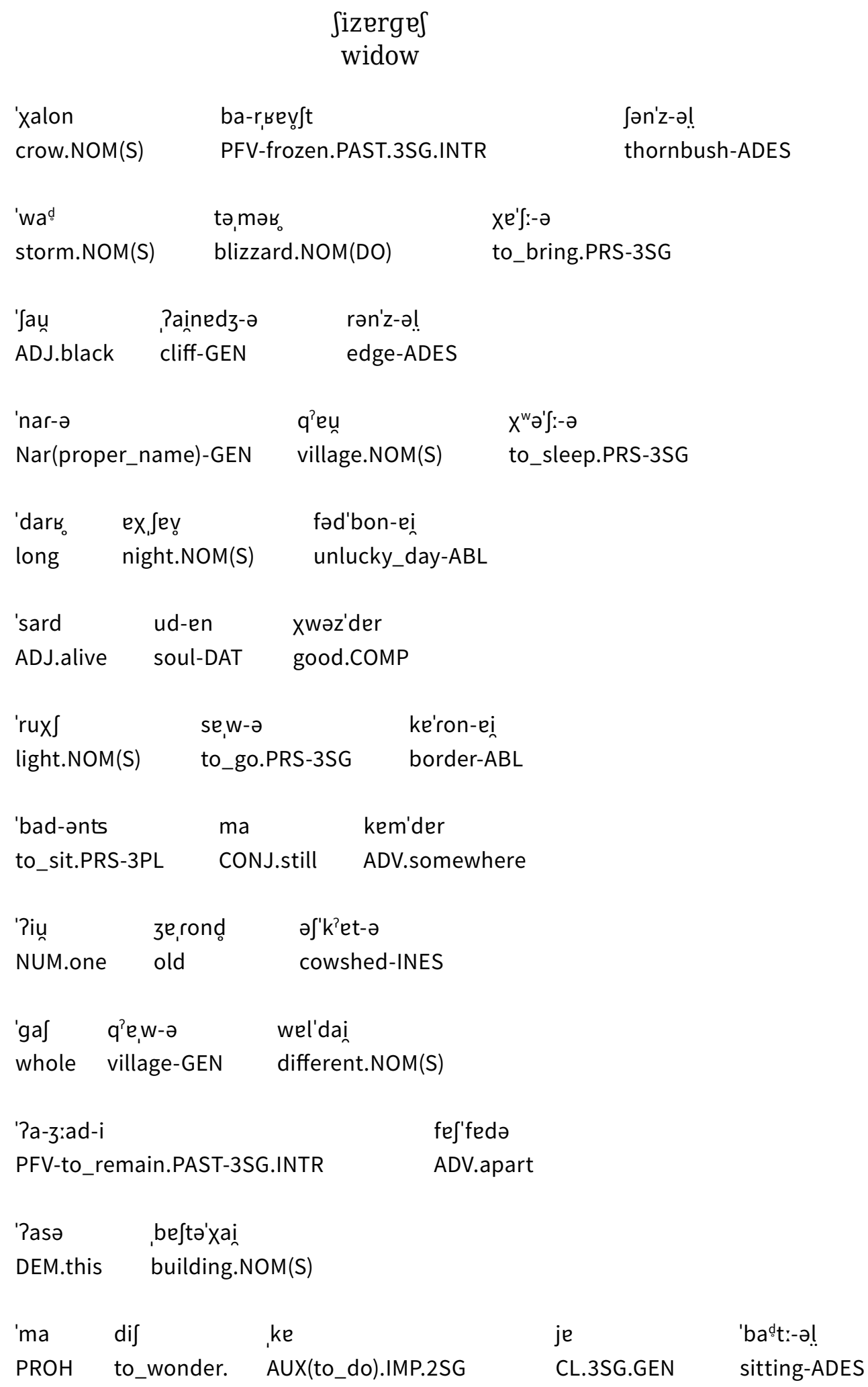




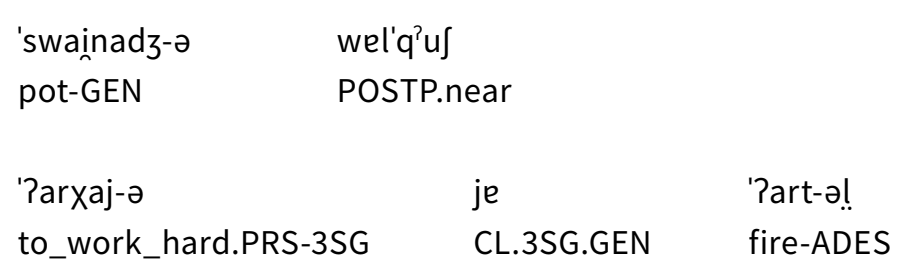

\begin{tabular}{|c|c|c|c|}
\hline 'Piu & $\int a u n-$ dar-e'g̀ & uf & \\
\hline NUM.one & black-wear-PTCP & woman.NOM(S) & \\
\hline 'Partzeft-ə & $k e^{\prime} r e^{t}-t:-\partial$ & & \\
\hline hearth-GEN & edge-PL-INES & & \\
\hline fe'nək-me & en'gom & & \\
\hline ash-ALL & ADV.near & & \\
\hline 'bad-ənts & Jəve'l:eet-t:-e & & \\
\hline to_sit.PRS-3PL & young-PL-NOM & & \\
\hline $\mathrm{ti}$ & 'bевneg̊ & $5 \mathrm{i}$ & 'gom \\
\hline INT.AN.NOM(S) & ADJ.bare & INT.AN.NOM(S) & ADJ.naked \\
\hline
\end{tabular}




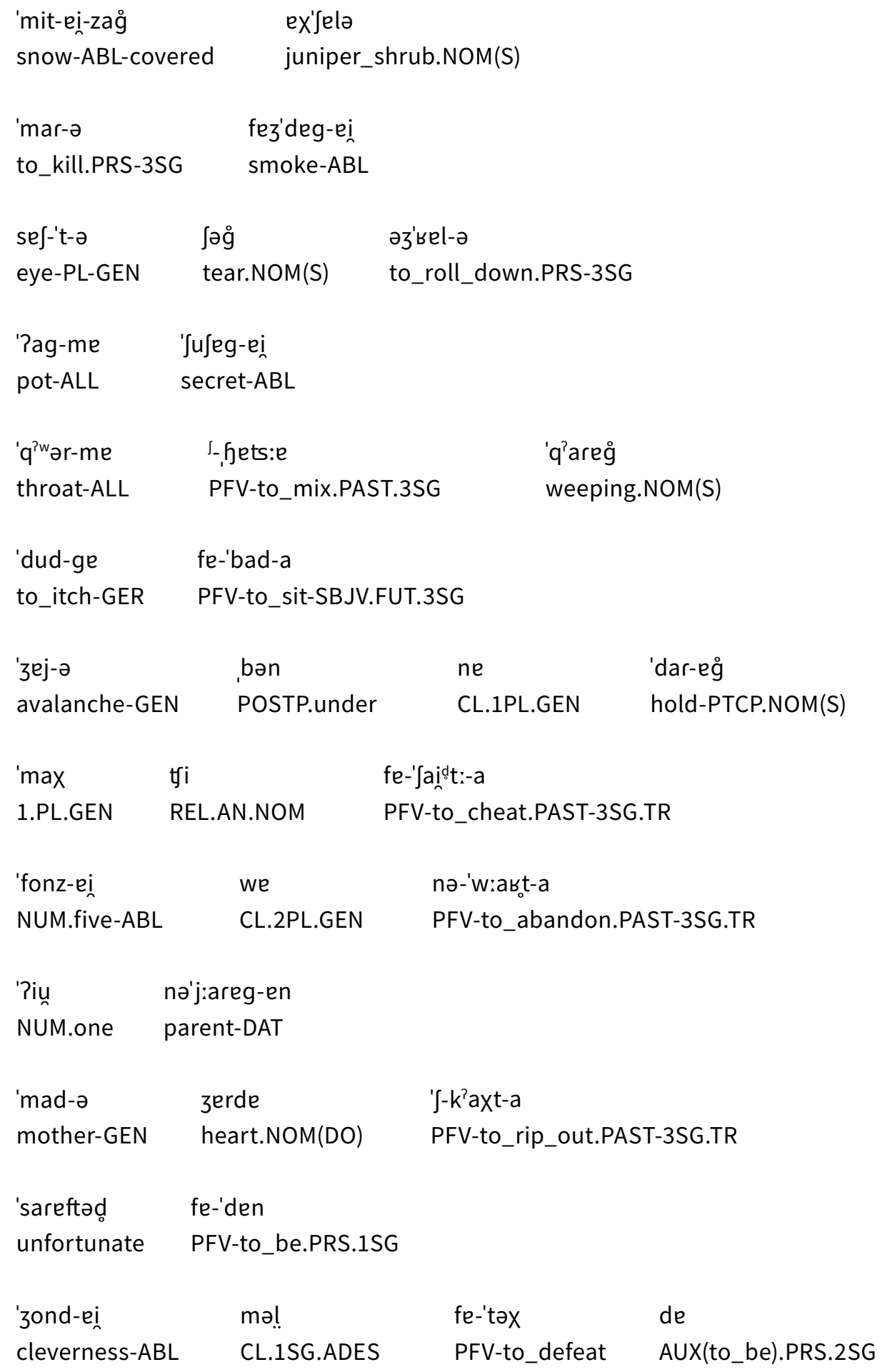




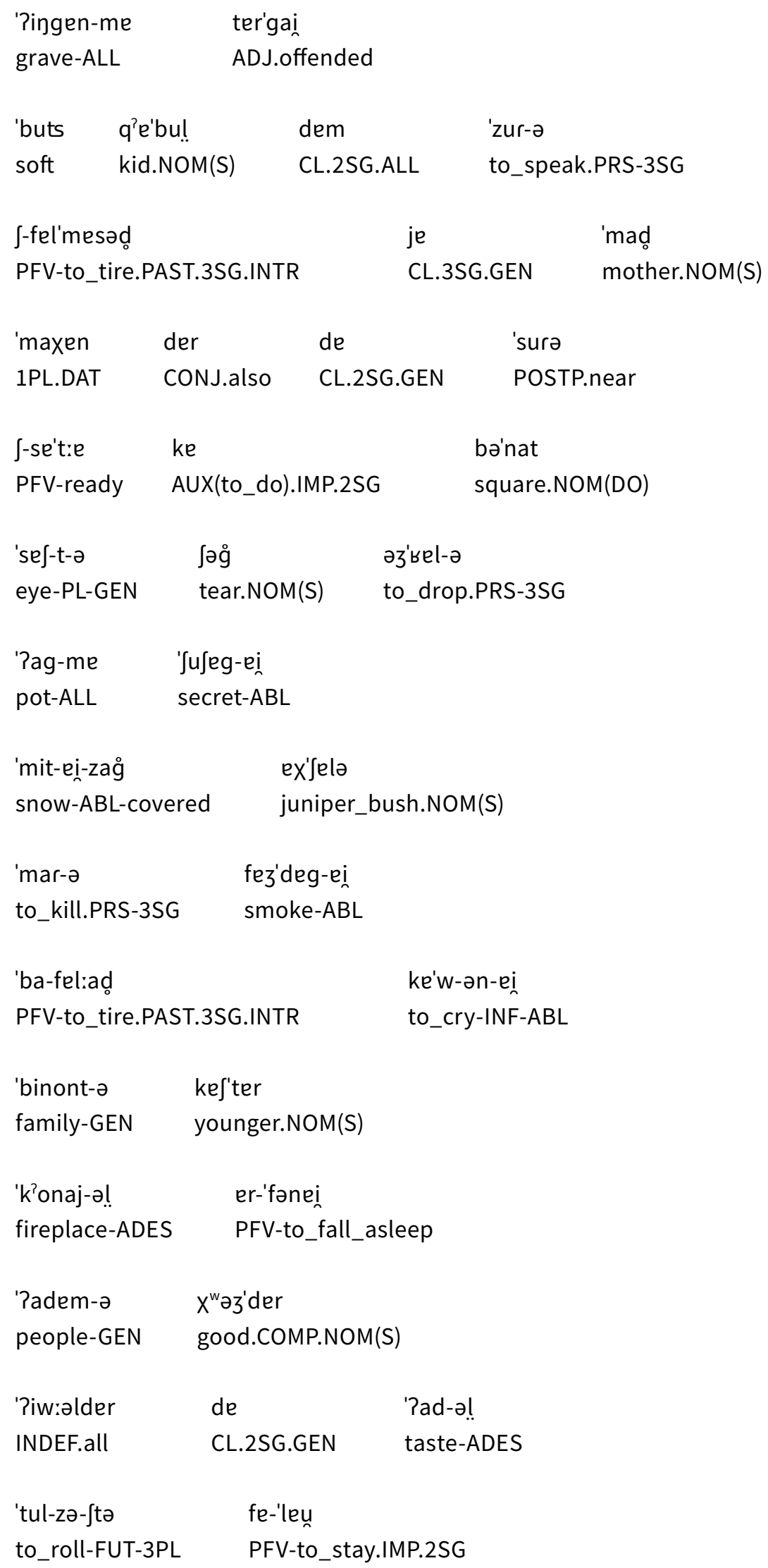




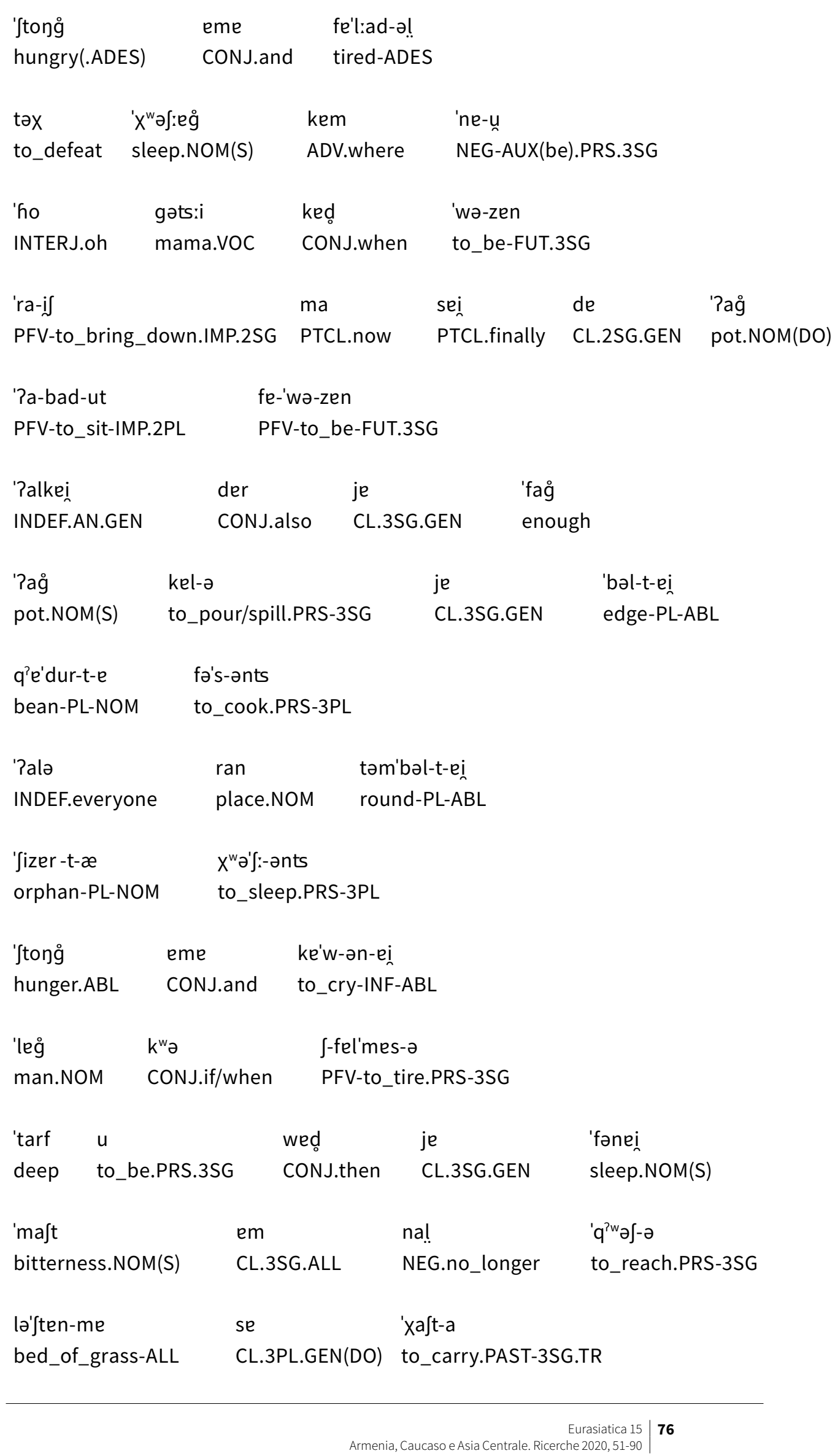




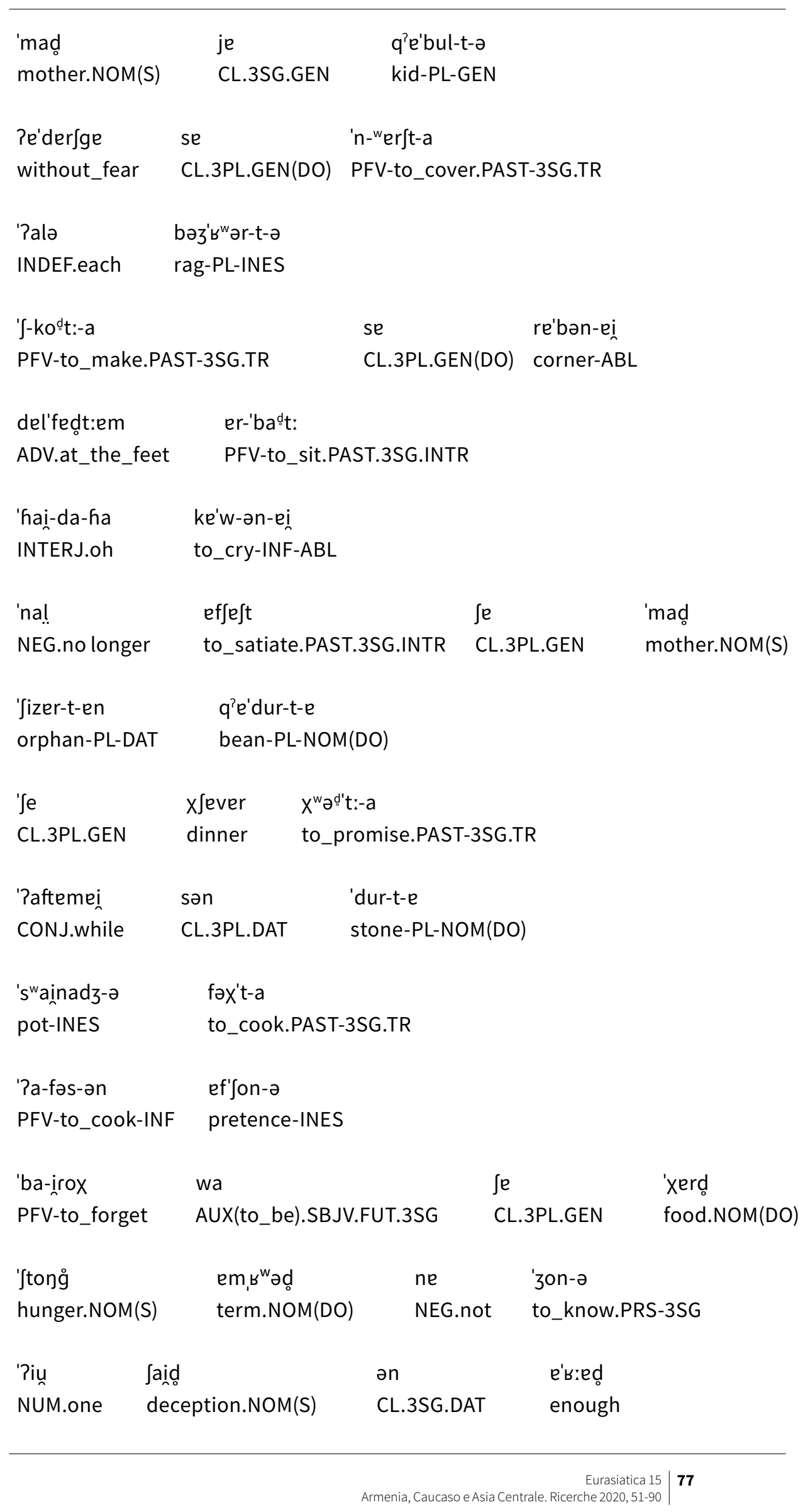




\section{Abbreviazioni}

\begin{tabular}{|c|c|}
\hline$A B L$ & Ablative \\
\hline ADES & Adessive \\
\hline ADJ & Adjective \\
\hline ADV & Adverb \\
\hline ALL & Allative \\
\hline AN & Animate \\
\hline AUX & Auxiliary \\
\hline $\mathrm{CL}$ & Clitic \\
\hline COMP & Comparative \\
\hline CONJ & Conjunction \\
\hline DAT & Dative \\
\hline DEM & Demonstrative \\
\hline DO & Direct Object \\
\hline FUT & Future \\
\hline GEN & Genitive \\
\hline GER & Gerund \\
\hline IMP & Imperative \\
\hline INDEF & Indefinite \\
\hline INES & Inessive \\
\hline INF & Infinitive \\
\hline INT & Interrogative \\
\hline INTERJ & Interjection \\
\hline INTR & Intransitive \\
\hline NEG & Negation \\
\hline NOM & Nominative \\
\hline NUM & Numeral \\
\hline PAST & Past \\
\hline PFV & Perfective \\
\hline PL & Plural \\
\hline POSTP & Postposition \\
\hline $\mathrm{PROH}$ & Prohibitive \\
\hline PRS & Present \\
\hline РTCT & Participle \\
\hline REL & Relative \\
\hline $\mathrm{S}$ & Subject \\
\hline SG & Singular \\
\hline SBJV & Subjunctive \\
\hline TR & Transitive \\
\hline VOC & Vocative \\
\hline
\end{tabular}




\section{Appendice I - Kosta Chetagurov: «B бурю»}

Pubblichiamo qui sotto il testo russo della poesia «V burju», accompagnato da una traduzione letterale per permettere un più agile confronto con il corrispondente testo osseto.

\section{В бурю}

Буря по ущелью

облака несет,

Вихрем и метелью,

Кружится, ревет...

Снегом забивает

Щели между скал.

Стонет, завывает,

Плачет, как шакал.

В каменной постели,

В ледяной коре,

Мрет, как в подземелье,

Как в глухой норе,

Горного потока

Неумолчный шум...

На скале высоко

Замер и аул.

Сакли, словно гробы

Из гранитных плит,

Прячутся в сугробы...

Сон везде царит.

Только наддорогой,

Под карнизом скал,

В сакельке убогой

Свет не угасал...

Дети полукругом

У огня сидят...

Ссорятся друг с другом, -

Есть давно хотят.

Мать их унимает, -

Бедная вдова! - -

Знай, - все раздувает

Мерзлые дрова.

Дети терпеливо

смотрят на таган...

\section{Durante la tempesta}

La tempesta lungo la gola

trasporta le nubi, con vortice e tormenta, gira intorno, infuria.

Riempie di neve

le crepe fra le rocce.

Geme, ulula.

piange come uno sciacallo.

Nel letto di pietra,

in una crosta di ghiaccio,

si affievolisce, come in un sotterraneo,

come in un buco morto,

di un torrente montano

il rumore incessante...

In cima alla roccia

si è fermato anche il villaggio.

I casolari sono letteralmente delle tombe

di lastre di granito,

si nascondono fra i cumuli di neve...

ovunque regna il sonno.

Solo sopra la via, sotto la grondaia delle rocce, in un piccolo tugurio la luce non si è spenta...

Dei bambini in semicerchio siedono di fronte al focolare... bisticciano fra loro, da tempo hanno fame.

La madre li rimprovera, povera vedova!

Sappi(lo), - continua a soffiare sulla legna congelata.

I bambini pazientemente guardano il treppiede... 


\begin{tabular}{ll} 
Вот зевнул лениво & ecco che pigramente ha sbadigliato \\
Младший мальчуган... & il ragazzino più piccolo... \\
Холод пронимает, & Il freddo è penetrante, \\
Адрема долит... & ma la sonnolenza prevale... \\
Ежится...зевает... & si rannicchia... sbadiglia... \\
Повалился...спит... & crolla a terra... dorme... \\
Щепки разгорелись... & I tizzoni hanno preso fuoco... \\
Котелок кипел... & la pentola bolliva (già)... \\
Дети не дождались, - & I bambini non ce l'hanno fatta, - \\
Сон их одолел... & Il sonno li ha sopraffatti... \\
Мать их уложила & La madre li ha coricati \\
На тахту рядком, & vicini sul divano, \\
Бережно прикрыла & li ha coperti piano piano \\
Их своим платком... & con il proprio scialle... \\
И легко им стало & E si sono tranquillizzati \\
В мире светлыхгрез... & nel mondo dei dolci sogni... \\
Мать лишь не сдержала & Solo la madre non è riuscita \\
Затаенныхслез... & a trattenere le lacrime nascoste... \\
Твердость изменила, & La durezza l'ha tradita, \\
Страшно стало ей, - & Si è terrorizzata, - \\
Ведь она варила & poiché stava cuocendo \\
Камни для детей. & pietre per i figli. \\
(Сһеtаgигоv 1951а, 20-2) & \\
\hline &
\end{tabular}

\section{Appendice II - Dall'archivio di Gappo Baev ${ }^{22}$}

L'ultima sezione contiene l'edizione sinottica di materiale finora inedito: si tratta di due versioni in lingua tedesca della poesia «Sidzærgæs», scritte originariamente a macchina. Entrambe si trovano nell'archivio personale di Gappo Baev, oggi conservato alla Staatsbibliothek di Berlino (Ziesche 2002, 9), ${ }^{23}$ più precisamente nel quarto di otto grossi faldoni (Nachlaß Georg Gappo Baiews, Abteilung IV, 16 - Übersetzungen aus dem Ossetischen). La prima traduzione (f. $6 r$, su due colonne), di servizio, è verosimilmente dello stesso Gappo Baev, la seconda (f. 34 r/v), più libera e poetica, della scrittrice

22 Nel commento (Chetagurov 1951a, 350-1) vengono riportate tre quartine, che si leggono nella versione pubblicata su Severnyj Kavkaz (nr. 50 del 1889) dopo i versi 16, 24 e 40, e sono invece assenti nel manoscritto su cui si basa l'edizione.

23 Baiew, Georg Gappo (1869-1939). Sprachforscher, 1926-1938 Dozent der Ossetischen Sprache an der Auslandshochschule in Berlin. 
Gertrud von Wenckstern (1870-1936), moglie del linguista (iranista) tedesco Karl Hadank (1882-1945). Quest'ultimo, che seguì le lezioni di lingua osseta tenute da Gappo Baev all'Istituto di Orientalistica di Berlino,${ }^{24} \mathrm{fu}$ fra l'altro impiegato dalla Wehrmacht in qualità di istruttore su lingua, vita e costumi dei curdi nell'ambito di un'operazione militare da svolgere nell'Iraq settentrionale nel 1943 (Lemke, Rosbeiani 2018, 18-29). Il materiale testuale, che arricchisce ulteriormente lo spettro di traduzioni dell'opera di Kosta, è preceduto da un brevissimo schizzo biografico del deuteragonista.

Georgij (Gappo) Vasil'evič Baev (1870-1939), in osseto Bajaty Gappo, è un importante esponente della vita politica e culturale osseta nell'ultimo quarto del XIX secolo e nel primo di quello successivo. In virtù della sua indefessa attività in vari settori della vita pubblica, egli è passato alla storia come poliedrico rappresentante dell'intelligencija osseta prerivoluzionaria: avvocato, pubblicista, politico, economista, amministratore, critico letterario, scrittore, folklorista, insegnante e traduttore, fu sindaco di Vladikavkaz (Dzalaeva 2016, 154) e partecipò attivamente all'organizzazione dell'editoria, fondando la rinomata casa editrice Ir (Darčieva 2015, 54), e dell'istruzione in lingua osseta. Come abbiamo visto, egli fu anche responsabile, nel bene e nel male, della prima edizione di Iron fœendyr e ne curò anche la quarta, quando già si trovava da emigrato in Germania, sua seconda patria (Chetagurov 1922). In un breve schizzo autobiografico, redatto in tedesco fra la primavera del 1930 e l'inverno del 1934, egli si presenta così: Georg-Gappo, Università di Odessa, avvocato, sindaco di Vladikavkaz, scrittore, difensore degli interessi del popolo, attualmente docente presso l'Istituto di Orientalistica di Berlino, membro dell'Unione accademica russa (Darčieva, Darčiev 2019, 176, 178). Dopo aver accolto con animo sereno la rivoluzione di febbraio, in seguito al colpo di mano bolscevico passò apertamente dalla parte dei bianchi, emigrando al termine della guerra civile prima a Tbilisi e quindi, in seguito all'occupazione della Georgia da parte dell'Armata Rossa, a Istanbul; da lì si trasferì poi in Germania, dove visse e lavorò fino alla morte, senza poter rivedere il suolo patrio. In epoca sovietica la sua figura, per ragioni ideologiche, fu oggetto di giudizi estremamente negativi e la sua opera di fatto dimenticata (Magometov, Čedžemov 2014, 45); oggi invece si cerca, sine ira ma non sine studio, di recuperare e rivalutare la sua eredità. In questo senso il suo archivio costituisce una preziosa e piuttosto ricca miniera che senza dubbio merita di essere sfruttata (Uarziati 1997, $28=2007$,

24 Nella prefazione ad un lavoro di dialettologia curda, Hadank, al quale, fra l'altro, dobbiamo anche la descrizione del contenuto del Nachlaß, menziona il proprio debito di riconoscenza al maestro di un tempo (Hadank 1930, xvi). 
470). ${ }^{25}$ Il materiale qui pubblicato è solo un piccolissimo esempio dei tesori nascosti che attendono ancora di essere riportati alla luce.

\section{Aus dem Diwan des Ossetischen Dichters \\ Kosta Chetaguroffs \\ [6a] Die Waisenhüterin}

\section{[34r] Die Weisenmutter Aus dem DIWAN des OSSETISCHEN DICHTERS \\ Kosta Chetaguroffs (1859-1906) \\ «Iron fandyr»}

Der Rabe erstarrte auf dem Dornbusche.

Der Sturm häuft Schneegestöber. Frierend im Dornstrauch birgt sich der Rabe. Wirbelnder Schnee deckt alle Gehege. Hoch in dem schwarzen Felsengebirge Auf dem Gipfel des schwarzen Felsens. Schlummert Dorf Nar am steinigen Stege.

Tief schlummert Dorf Nar.

Für die Seele ist eine lange Nacht, Besser als übles Leben.

Es scheint ein Lichtchen am Rande, Man sitzt noch irgendwo.

Bei einem alten Viehstall, Außerhalb des ganzen Dorfes Abseits vom Dorfe liegt - wie vergessen Dicht bei dem Stall das Hüttlein, das kleine; Liegt abseits dieses Gehöft Dort eine Frau, im Trauergewande Müht sich am Herd bei glimmendem Scheine.

Wundre Dich nicht, daß sie noch sitzt.....

Bei dem Kessel, nahe eine Trauertragende

Frau

Bemüht sich über dem Feuer.

Am Rande des Herdes, dicht an der

Feuerasche,

Sitzen die Kinder,

Einige barfuß, einige nackt.

Vor Kälte und Hunger fürchtet

sich auch der Wolf,

Der Todesgeist mühelos,

Führt solche mit.

Weinet nicht, meine Sonnen, -

Spricht zu ihnen ihre Mutter, -

"- Die Bohnen werden schon kochen,

Sitzt doch noch ein wenig stille["].

Neben dem Herde, nah bei der Asche Hungernde Kinder: all ihre Röckchen Dünn und zerrissen. Eines der Kleinen Hat keine Schuhe, eines kein Söckchen!

Teufelskirsche, voll von Schnee, Qualmt mit ihrem Rauch.

Die Tränen fließen

Geheim in den Kessel nieder. Hunger und Kälte: starke Gewalten, Können den Wolf, den wildesten zwingen. Stehen im Bunde treu mit dem Tode, Dem sie sein Opfer mühelos bringen.

Sagt zu den Kindern tröstend die Mutter: "Ihr meine Sonnen! müsst doch nicht weinen! Glaubt mir, die Bohnen werden gleich kochen; Habt doch Geduld! seid stille, ihr Kleinen! Schnee-nasser Dornstrauch kann ja nicht brennen! Flämmlein ersticken im Rauche wieder ---Heimliche Tränen fallen und rinnen, Rinnen am Kessel leise hernieder.

25 Lo studioso esprime l'auspicio che, dopo le ceneri di Gappo Baev, oggi conservate nel cimitero che cinge la chiesa della Natività di Maria, sulla collina di Vladikavkaz, anche il suo archivio possa tornare in patria, almeno in forma di copia. 82 


\begin{tabular}{ll}
\hline $\begin{array}{l}\text { Ein Klageseufzen stieg bis an die Kehle..... } \\
\text { - "Möge unser Pfleger }\end{array}$ & $\begin{array}{l}\text { Da stöhnt die Mutter zornige Klage: } \\
\text { "Unser Ernäher - er ist gegangen! } \\
\text { Mit Qualen sitzen unter der Lawine, }\end{array}$ \\
$\begin{array}{l}\text { Der uns hat getäuscht } \\
\text { Mag die Lawine kalt ihn umfangen! }\end{array}$ \\
\hline $\begin{array}{l}\text { Er hat euch fünf hinterlassen, } \\
\text { Eure Mutter, damit hat er }\end{array}$ & Klüger wie ich hast Rat du gefunden! \\
Mutters Herz ausgerissen... & Lieb! Alle Sorgen trugst du zum Grabe! \\
Ich bin doch obdachlos geworden. & Ich soll allein die Waisen ernähren, \\
\hline Mit Deinem Verstand hast Du mich & Ob ich mein Herz zerrissen auch habe. \\
überwältigt, & Hör, deinen Liebling, wie er dir wimmert \\
O, mein lieber Mann, & Von seiner Mutter, ach von der matten! \\
Du bist von den Waisen entflohen, & Rüste nun, rüste unsere Ruhstatt \\
Ins Grab entledigt! & Nahe bei dir im eisigen Schatten!" \\
\hline
\end{tabular}

[6b] Dein Lieblingskind ruft zu Dir:

"Daß seine Mutti ist schon übermüdet

Und mache einen Platz neben Dir,

Auch für uns fertig["].

\section{Es fließen die Tränen \\ Geheim an dem Kessel nieder, \\ Schneevolle Teufelskirsche \\ Qualmt mit ihrem Rauch.}

\section{Er ist müde geworden}

Vom Weinen, der Jüngste von der Familie,

An dem Herde ist er eingeschlafen,

Der Beste der Leute.

Nach Dir alle werden

Ins Schlafen hineinrollen, Warte doch.

Über Hungernden und Müden,

Wo hat nicht Kraft der Schlaf?

["]O, Mutti, wann wird es doch sein, Nimm doch Deinen Kessel!["] -

- "Setzt euch noch ein wenig, Wird jeder seine Portion doch haben["].

Den Waisenkindern die Bohnen

Nannte sie ihr Abendessen, -

Dabei aber kochte sie

Ihnen im Kessel kleine Steinchen.

Damit des Kochens wegen

Könnten sie ihr Essen vergessen.

Der Hunger kennt doch keine Zeit,

Ein Betrug ist ihm genug.

Der Kessel läuft über, -

"Die Bohnen kochen!"

An verschiedenen Winkeln gekrümmt,

Schlafen die Waisenkinder.
Heimliche Tränen fallen und rinnen,

Rinnen am Kessel leise hernieder --:

[34v] Schnee-nasser Dornstrauch kann ja

nicht brennen!

Flämmlein ersticken im Rauche wieder!

Müde vom Weinen schläft nun der Jüngste.

Liebling und Herzblatt ist er von allen.

Schlafe nur! Bald sind deine Geschwister Kraftlos wie du in Schlummer gefallen.

Schlaf hat Gewalt. Die Hungernden, Müden

Zwingt er zur Ruh und lässt sie nicht wieder ----

"Hört nur, ihr Kinder, Wasser im Kessel

Summt euch beim Kochen Märchen und Lieder."

"'Nimm doch vom Feuer, Mutter den Kessel Nimm ihn vom Feuer! Gib uns zu essen!"” "Wartet ein wenig, wartet noch Kinder, Werdet bald allen Hunger vergessen!" Steinchen im Kessel kochte die Mutter. Sagte den Kindern: "Bohnen, die süssen, Geb ich euch bald! ihr sollt ja nur warten, Weil sie ein Weilchen kochen noch müssen!"

"Bohnen sind gar"! Das Wasser im Kessel Hat es den Waisen siedend gesungen --Sang, bis sie schliefen, tief, wie die Menschen, Wenn sie von Leid und Tränen bezwungen.

Es kann die Mutter sie betten, Betten aus Stroh, mit Lumpen sie decken: Alle die harten Qualen des Lebens Können die Schläfer jetzt nicht erschrecken. 
Wenn der Mensch wird

Vom Hunger und Weinen übermüdet, Dann ist sein Schlaf tief, Er hört nichts mehr von den Bitternissen des Lebens.
Bei ihren Kindern wacht nun die Mutter --Könnte die Arme schlummernd doch liegen --Aber die heissen Tränen sie strömen Strömen und wollen nimmer versiegen -----. Übersetzt von Gertrud von Wenckstern (Frau Dr. Hadank).

\section{Bibliografia $^{26}$}

Abaev, I.; Farneev, K. (1931). «Kosta [Xetæggaty Leuany tyrt [sic!], 1863-1906]». Literaturnaja ènciklopedija (Enciclopedia letteraria), tomo 5. s.l.: Izdatel'stvo kommunističeskoj akademii, coll.503-7. http://feb-web.ru/feb/litenc/encyclop/le5/le5-5031.htm.

Abaev, V.D. (1950). Kosta. Stalinir: Gosizdat Jugo-Osetii.

Abaev, V.D. (1961). Kosta Chetagurov i ego vremja (Kosta Chetagurov e il suo tempo). Tbilisi: Izdatel'stvo Sojuza pisatelej Gruzii Zarja Vostoka.

Abaev, V.I. (1939). «Kosta Chetagurov. Narodnyj poèt Osetii» (Kosta Chetagurov. Poeta popolare dell'Ossezia). Zvezda. Ežemesjačnyj literaturnochudožestvennyj i obščestvenno-političeskij žurnal (Stella. Rivista mensile artistico-letteraria e politico-sociale), 9, 153-5 [ristampato in versione estesa in Kučiev 1989, 3-16].

Abaev, V.I. (1952). «Grammatičeskij očerk osetinskogo jazyka» (Schizzo grammaticale della lingua osseta). Kasaev, A.M. (a cura di), Osetinsko-russkij slovar' (Dizionario osseto-russo). Moskva: Gosudarstvennoe izdatel'stvo inostrannych i nacional'nych slovarej, 441-539.

Abaev, V.I. (1959). Grammatičeskij očerk osetinskogo jazyka (Schizzo grammaticale della lingua osseta). Ordžonikidze: Severo-Osetinskoe knižnoe izdatel'stvo.

Abaev, V.I. (1960). «Čto značit Kosta dlja osetinskogo naroda» (Che cosa significa Kosta per il popolo osseto). Izvestija Jugo-Osetinskogo naučnoissledovatel'skogo instituta Akademii Nauk Gruzinskoj SSR (Notizie dell'istituto di ricerca scientifica dell'Ossezia meridionale presso l'Accademia delle Scienze della Repubblica Socialista Sovietica di Georgia), 10, 72-80.

Abaev, V.I. (1964). A Grammatical Sketch of Ossetic. Edited by Herbert H. Palmer; translated by Steven P. Hill. Bloomington: Indiana University [= International Journal of American Linguistics 30, 4; traduzione dal russo di Abaev 1952 e 1959].

Abaev, V.I. (1990). Izbrannye stat'i. Religija, fol'klor, literatura (Articoli scelti. Religione, folclore, letteratura). Vladikavkaz: Izdatel'stvo Ir.

Apresjan, G.Z. (1962). Vstreči s Kosta. Očerki (Incontri con Kosta. Lineamenti). Ordžonikidze: Severo-Osetinskoe knižnoe izdatel'stvo.

Avruščenko, V.I.(1940). "Kosta Chetagurov». Chetagurov, K., Dunja. P'esa. Moskva; Leningrad: Gosudarstvennoe izdatel'stvo «Iskusstvo», 97-111.

Bekoev, G.G. (1925). «Poèt-graždanin» (Poeta-cittadino). Izvestija osetinskogo naučno-issledovatel'skogo instituta (Notizie dell'istituto osseto di ricerca scientifica), 1, 28-39 [ristampato in Bekoev 1982, 29-50].

Bekoev, G.G. (1982). Literaturno-kritičeskie stat'i (Articoli critico-letterari). Predislovie napisal, teksty podgotovil i primečanija sostavil Chadži-Umar Alborty. Cchinvali: Izdatel'stvo «Iriston». 
*Berkov, P.N. (1969). «Sidzærgæs» (La vedova). Fidiuæg, 8, 69-72.

Bigulaeva, I.S. (2015). Kosta Levanovič Chetagurov. Naučnaja biografija (Kosta Levanovič Chetagurov. Biografia scientifica). Vladikavkaz: Proekt-Press.

Bociev, B.T. (1941). «Zaščitnik bednjakov» (Difensore dei poveri). Fadeev, A.A. (a cura di), Kosta Chetagurov. Sbornik pamjati velikogo osetinskogo poèta (Kosta Chetagurov. Miscellanea in memoria del grande poeta osseto). Moskva: OGIZ, Gosudarstvennoe izdatel'stvo chudožestvennoj literatury, 164.

Chadarceva, A.A. (1956). O žizni i tvorčestve Kosta Chetagurova (pomošč lektoru) (Sulla vita e sull'opera di Kosta Chetagurov. Sussidiario per l'insegnante). Ordžonikidze: Severo-Osetinskoe knižnoe izdatel'stvo.

Chetagurov, K.(1922). Iron fændyr (Lira osseta). Biografi nyfysta Bajaty Gappo, cyppæræm rauağd. Berlin: Rauadzæg Gutnaty Elbyzdyqo.

Chetagurov, K.L.; Chetægkaty, K. (1939). Osetinskaja lira. Iron fændyr (Lira osseta). Moskva: Gosudarstvennoe izdatel'stvo «Chudožestvennaja literatura»; Mæskuy: Padzaxadon rauağdad «Aiv literaturæ».

Chetagurov, K.L. (1951a). Sobranie sočinenij v trëch tomach (Opere in tre volumi). Tom vtoroj, Chudožestvennye proizvedenija, napisannye na russkom jazyke (Opere artistiche, scritte in lingua russa). Moskva: Izdatel'stvo Akademii Nauk SSSR.

Chetagurov, K.L. (1951b). «Vladikavkazskie pis'ma» (Lettere da Vladikavkaz). Chetagurov, K.L., Sobranie sočinenij v trëch tomach (Opere in tre volumi). Tom tretij, Publicistika, pis'ma (Pubblicistica. Lettere). Moskva: Izdatel'stvo Akademii Nauk SSSR, 12-18.

Chetagurov, K.L. (1959). Kosta Chetagurov (1859-1906). Kratkaja spravka o žizni i tvorčestve (Kosta Chetagurov (1859-1906). Breve nota su vita e opere). Ordžonikidze: Severo-Osetinskoe knižnoe izdatel'stvo.

Chetagurov, K.L. (1961). Sobranie sočinenij v pjati tomach (Opere in cinque volumi). Tom pjatyj, Pis'ma, zapisi, nabroski, delovye bumagi (Lettere. Appunti. Bozze. Documenti). Moskva: Izdatel'stvo Akademii Nauk SSSR.

Chetagurov, K.L. (1999). Polnoe sobranie sočinenij v pjati tomach (Tutte le opere in cinque volumi), tom pervyj. Vladikavkaz: Respublikanskoe izdatel'skopoligrafičeskoe predprijatie im. V.A. Gassieva.

Chetagurov, K.L. (2009). Iron fændyr. Zærdæjy sağæstæ, zardžytæ, kaddžytæ æmæ æmbisændtæ (Lira osseta. Pensieri del cuore, canti, poemi epici e favole). Dzæudžyqæu: Ir.

Chetagurov, K.L. (2012). Osoba (ètnografičeskij očerk) (Osoba. Schizzo etnografico). Vladikavkaz: Izdatel'sko-poligrafičeskoe predprijatie im. V. Gassieva.

Čursin, G.F. (1925). Osetiny. Ètnografičeskij očerk (Gli osseti. Schizzo etnografico). Tiflis: Tipografija gaz. Zarja Vostoka [estratto dalla rivista Trudy Zakavkazskoj associacii (Lavori dell'associazione transcaucasica), ser. 1, vypusk 1: Materialy po izučeniju Gruzii: Jugo-Osetija, 132-232].

Darčieva, S.V. (2015). «Kul'turno-prosvetitel'skaja dejatel'nost' G.V. Baeva (konec XIX veka-1939 g.)» (L'attività culturale-educativa di G.V. Baev. Fine del XIX-1939). Istoričeskie, filosofskie, političeskie ijuridičeskie nauki, kul'turologija i iskusstvovedenie. Voprosy teorii i praktiki (Scienze storiche, filosofiche, politiche e giuridiche, studi culturali e storia dell'arte. Problemi. Questioni di teoria e pratica), 10(60), 3, 52-6. https://www.elibrary.ru/item. asp? id=24155539.

Darčieva, S.V.; Darčiev, A.V. (2019). «Avtobiografičeskij očerk G.V. Baeva 'Iz moej žizni'» (Schizzo autobiografico di G.V. Baev 'Dalla mia vita'). Izvestija SOIGSI, 
34(73), 168-87. http://izvestiya-soigsi.ru/upload/articles/darchieva-darchiev.pdf.

Dzalaeva, K.R. (2016). «Vovlečenie predstavitelej mestnogo naselenija v gosudarstvenno-administrativnoe upravlenie $v$ processe formirovanija osnov graždanstvennosti i obščerossijskoj identičnosti na Severnom Kavkaze vo vtoroj polovine XIX-načale XX vV.) (II coinvolgimento di rappresentanti della popolazione locale nella gestione amministrativo-statale all'interno del processo di formazione delle basi della cittadinanza e dell'identità russa nel Caucaso settentrionale nella seconda metà del XIX-inizio del XX secolo). Genealogija narodov Kavkaza. Tradicija i sovremennost' (Genealogia dei popoli del Caucaso. Tradizione e contemporaneità), 8, 152-9. http:// soigsi.com/books/b17/genealogia_narodov_kavkaza_VIII.pdf.

Dzantiev, A.A. (2009). «Priloženie. Kosta Chetagurov, Iron fændyr. Osetinskaja lira (Podstročnyj perevod na russkij jazyk)» (Appendice. Kosta Chetagurov, Lira Osseta. Traduzione interlineare in lingua russa). Xetægkaty, K., Iron fændyr. Zærdæjysağæstæ, zardžytæ, kaddžytæ æmæ æmbisændtæ (Lira osseta. Pensieri del cuore, canti, poemi e favole); Chetagurov, K., Osetinskaja lira. Dumy serdca, pesni, poèmy, basni (Lira osseta. Pensieri del cuore, canti, poesie, favole). Mæskuy-Dzæudžyqæu; Moskva-Vladikavkaz: D\&D, 297-382.

Dzasochov, G.B. (1909). Kosta Chetagurov. Kritiko-biografičeskij očerk. Stichotvorenija. Pis'ma i vospominanija. Dokumenty k biografii. Portrety (Kosta Chetagurov. Breve schizzo biografico. Poesie, lettere e ricordi. Documenti relativi alla biografia. Ritratti). Rostov na Donu: Ėlektro-tipografija M.I. Guzman [reprintnoe izdanie, Možajsk, Izdatel'stvo «Menedžer», 1999].

Dziccojty, J.A. (2017). «Motiv varki kamnej v stichotvorenii K. Chetagurova 'Sidzærgæs'» (Il motivo della cottura dei sassi nella poesia di K. Chetagurov 'La madre degli orfani'). Dar'jal, 6. http://www.darial-online. ru/2017_6/dzitzoyti.shtml.

Epchiev, T.A. (1951). «O tvorčestve Kosta Chetagurova (Predislovie $k$ izdaniju)» (Sull'opera di Kosta Chetagurova. Introduzione all'edizione). Chetagurov, K., Sobranie sočinenij v trëch tomach (Opere in tre volumi). Tom 1, Iron fændyr. Osetinskaja lira (Lira osseta). Moskva: Izdatel'stvo Akademii Nauk SSSR, 5-58.

Fadeev, A.A. (1941). «Bratstvo narodov» (La fratellanza dei popoli). Fadeev, A.A. (a cura di), Kosta Chetagurov. Sbornik pamjati velikogo osetinskogo poèta (Kosta Chetagurov. Miscellanea in memoria del grande poeta osseto). Moskva: OGIZ, Gosudarstvennoe izdatel'stvo chudožestvennoj literatury, 3-5 [ripubblicato come Fadeev 2009; ristampato con alcune omissioni in Kučiev 1989, 287-9].

Fadeev, A.A. (2009). «Bratstvo narodov» (Fratellanza dei popoli). Vestnik Vladikavkazskogo naučnogo centra (Bollettino del centro scientifico di Vladikavkaz), 9(5), 26-7. https://cyberleninka.ru/article/n/bratstvonarodov/viewer.

Gabaraev, S.Š. (1959). Mirovozzrenie Kosta Chetagurova (La visione del mondo di Kosta Chetagurov). Moskva: Izdatel'stvo social'no-èkonomičeskoj literatury.

Gadiev, C.S. (1926). «Kosta Chetagurov. Pevec osetinskoj gorskoj bednoty» (Kosta Chetagurov. Cantore della miseria dei montanari osseti). Izvestija Osetinskogo naučno-issledovatel'skogo instituta kraevedenija (Notizie dell'Istituto scientifico osseto per lo studio delle tradizioni locali), 2, 445-63 [ristampato con alcune omissioni in Kučiev 1989, 53-77]. 
Gagkaev, K.E. (1957). O jazyke i stile Kosta Chetagurova (Sulla lingua e lo stile di Kosta Chetagurova). Ordžonikidze: Severo-Osetinskoe knižnoe izdatel'stvo.

Giordano, A.; Salvatori, M.; Tomelleri, V.S.(2019). «'ll cuore del nostro popolo è il mio campo arato'. Tre poesie in lingua osseta di Kosta Chetagurov». Comai, G. et al. (a cura di), Armenia, Caucaso e Asia Centrale. Ricerche 2019. Venezia: Ca' Foscari, 255-76. Eurasiatica. Quaderni di studi su Balcani, Anatolia, Iran, Caucaso e Asia Centrale, 12. http://doi.org/10.30687/97888-6969-340-3/013.

Guriev, T.A. (2009). Kosta. Selected Poems. Interlinear Translation by T.A. Guriev). Vladikavkaz: IPO SOIGSI.

Guriev, T.A. (a cura di) (2015). Iron-uyryssag-anglisag dzyrduat. Osetinskorussko-anglijskij slovar'. Ossetic-Russian-English Dictionary (Dizionario osseto-russo-inglese). Tom vtoroj: L-Ja. Vladikavkaz: IPC SOIGSI VNC RAN i RSO-A. http://soigsi.com/books/guriev2015.pdf.

Gutiev, K.C. (1951). «Kosta Chetagurov». Chetagurov, K., Sobranie sočinenij v trëch tomach (Opere in tre tomi). Tom pervyj, Osetinskaja lira, Chetag (Lira osseta. Chetag). Dzaudžikau: Gosudarstvennoe izdatel'stvo Severo-Osetinskoj ASSR, 5-25.

Hadank, K. (1930). Mundarten der Gûrân, besonders das Kändûläî, Auramânîund Bâdschälânî. Kurdisch-Persische Forschungen. Ergebnisse einer von 1901 bis 1903 und 1906 bis 1907 in Persien und der asiatischen Türkei ausgeführten Forschungsreise von Oskar Mann, fortgeführt von Karl Hadank, Abteilung III (Nordwestiranisch), Bd. Il. Berlin: Verlag der Preußischen Akademie der Wissenschaften in Kommission bei Walter de Gruyter \& Co.

Hartmann, M. (1874). Gedichte von Moritz Hartmann. Neue Auswahl. Stuttgart: Verlag der J.G. Cotta'schen Buchhandlung, https://reader.digitale-sammlungen.de//resolve/display/bsb11260219.html.

Ivanov, V. (1941). «Osetinskaja lira» (Lira osseta). Fadeev, A.A. (a cura di), Kosta Chetagurov. Sbornik pamjati velikogo osetinskogo poèta (Kosta Chetagurov. Miscellanea in memoria del grande poeta osseto). Moskva: OGIZ, Gosudarstvennoe izdatel'stvo chudožestvennoj literatury, 122-5 [ristampato in Kučiev 1989, 136-40].

Jubilej (1941). Jubilej Kosta Chetagurova 1859-1939. Xetægkaty K'ostajy jubilej 1859-1939 (Anniversario di Kosta Chetagurov 1859-1939). Ordžonikidze: Gosudarstvennoe izdatel'stvo Severo-Osetinskoj ASSR; Cægat Irystony ASSRy paddzaxadon rauağdad.

Khétagourov, K. (2005). Ossoba. Essai ethnographique (1894). L'Ossétie traditionelle vue par un ossète. Traduit du russe et commenté par Lora ArysDjanaïéva et laroslav Lebedynsky. Paris: Errance.

*Kodzati, A.M. (1999). «O sjužete 'Materi sirot'» (Sul soggetto della 'Madre degli orfani'). Osetinskaja filologija. Istorija i sovremennost' (Filologia osseta. Storia e contemporaneità), 3, 103-6, http://ossethnos.ru/philology/131o-syuzhete-materi-sirot.html.

Korzun, V.B. (1952). «Istorija izdanija sbornika 'Iron fandyr' K.L. Chetagurova» (Storia dell'edizione della raccolta 'Lira osseta' di K.L. Chetagurov). Groznenskij gosudarstvennyj pedagogičeskij institut. Učënye zapiski (Istituto pedagogico statale di Groznyj. Note scientifiche), 7, serija filosofskaja 1, serija filologičeskaja 4, 107-23.

Korzun, V.B. (1954). «Ob izučenii biografii i tvorčestva K.L. Chetagurova» (Sullo studio della biografia e dell'opera di K.L. Chetagurov). Izvestija Groznensko- 
go oblastnogo kraevedčeskogo muzeja (Notizie del museo regionale di cultura locale di Groznyj), 6, 55-72.

Korzun, V.B. (1957). Kosta Chetagurov. Očerk žizni i tvorčestva (Kosta Chetagurov. Schizzo su vita e opere). Moskva: Sovetskij pisatel'.

Kravčenko, G.I. (1959). «Kosta Chetagurov (1859-1906)». Učenye zapiski SeveroOsetinskogo gosudarstvennogo pedagogičeskogo instituta imeni K.L. Chetagurova (Note scientifiche dell'Istituto pedagogico dell'Ossezia settentrionale K.L. Chetagurov), 24, 3-26.

Kravčenko, G.I. (1961). Kosta Chetagurov. Žizn' i dejatel'nost' (Kosta Chetagurov. Vita e attività). Ordžonikidze: Severo-Osetinskoe knižnoe izdatel'stvo.

Kravčenko, V.N. (2008). Kosta, syn Leuana. 150-letiju so dnja roždenija Kosta Levanoviča Chetagurova posvjaščaetsja (Kosta, figlio di Levan. Dedicato al 150 anniversario della nascita di Kosta Levanovič Chetagurov). Stavropol': «Jurkit».

Kučiev, A.G. (1989). Ves'mir-moj chram...K 130-letiju so dnja roždenija Kosta Chetagurova (Tutto il mondo è il mio tempio...Per il 130 anniversario della nascita di Kosta Chetagurov). Ordžonikidze: «lr».

Kulov, K.D. (1939). «Velikij poèt osetinskogo naroda Kosta Chetagurov» (II grande poeta del popolo osseto Kosta Chetagurov). Chetagurov, K.L. (Chetægkaty, K.), Osetinskaja lira. Iron fændyr (Lira osseta). Moskva: Gosudarstvennoe izdatel'stvo Chudožestvennaja literatura; Mæskuy: Padzaxadon rauağdad Aiv literaturæ, 5-12.

Kulov, K.D. (1947). Velikij poèt osetinskogo naroda. Lekcija, pročitannaja 7 maja 1947 goda v gorode Dzaudžikau. Kosta-Chetagurovskie čtenija (II grande poeta del popolo osseto. Lezione tenuta il 7 maggio 1947 nella città di Vladikavkaz. Letture Kosta-Chetaguroviane). Dzaudžikau: Severo-Osetinskoe gosudarstvennoe izdatel'stvo.

Lemke, B.; Rosbeiani, P. (Hrsgg) (2018). Unternehmen Mammut. Ein Kommandoeinsatz der Wehrmacht im Nordirak 1943. Bremen: Falkenberg.

Magometov, A.A.; Čedžemov S.R. (2014). Kul'tura, intelligencija, obrazovanie. Istorija i teorija (na materialach osetinskogo naroda) (Cultura, intellighenzia, formazione. Storia e teoria su materiali riguardanti il popolo osseto). Vladikavkaz: Izdatel'stvo Severo-Osetinskogo gosudarstvennogo universiteta imeni K.L. Chetagurova.

Malinkin, A. (1941). «Poèzija Kosta Chetagurova» (La poesia di Kosta Chetagurov). Fadeev, A.A. (a cura di). Kosta Chetagurov. Sbornik pamjati velikogo osetinskogo poèta (Kosta Chetagurov. Miscellanea in memoria del grande poeta osseto). Moskva: OGIZ, Gosudarstvennoe izdatel'stvo chudožestvennoj literatury, 17-40.

Maurizio, M.; Tomelleri, V.S. (a cura di) (2018). Rivoluzione visiva attraverso visioni rivoluzionarie. Alfabeti, cinema e letteratura in URSS. QuadRi, Quaderni di Ricognizioni, 8. Torino: Dipartimento di Lingue e Letteratura straniere e Culture moderne, Università di Torino.

*Nesin, A. (1979). «Svjatoj Jomer. Islamskij chalif. Brodil nočju po ulicam Mediny.... (Il santo Jomer. Califfo islamico. Errava di notte per le strade di Medina). Inostrannaja literatura, 10, 235-6.

Nikitin, I.S. (1915). Izbrannye stichotvorenija (Poesie scelte). Moskva: Izdanie Tva 'Rodnaja reč" [Rodnaja reč' 30]. http://ostdok.de/id/BV020338612/ $\mathrm{ft} / \mathrm{bsb} \odot \odot 107861$ ?page $=1 \& \mathrm{c}=$ solrSearch0stdok.

Puškin, A.S. (2013). Il viaggio a Arzrum. A cura di A. Ferrari; traduzione, note e appendice a cura di S. Pelusi. Milano: Biblion. 
Salagaeva, Z.M. (1959). Kosta Chetagurovi osetinskoe narodnoe tvorčestvo (Kosta Chetagurov e la produzione popolare osseta). Ordžonikidze: SeveroOsetinskoe knižnoe izdatel'stvo.

Semënov, L.P. (1951). «Kosta Chetagurov i russkaja literatura» (Kosta Chetagurov e la letteratura russa). Chetagurov, K., Sobranie sočinenij v trëch tomach (Opere in tre tomi). Tom vtoroj, Stichotvorenija, poèmy, proza, dramaturgija (Poesie, poemi, prosa, drammaturgia). Dzaudžikau: Gosudarstvennoe izdatel'stvo Severo-Osetinskoj ASSR, 5-16.

Tedety (Skifiron), Rjurik K. (2009). Kosta v žizni. Sistematičeskij svod vospominanij sovremennikov, sobstvennych ego svidetel'stvidrugich materialov (Kosta dal vivo. Raccolta sistematica dei ricordi dei contemporanei, delle sue testimonianze e di altri materiali). Cchinval: «Južnaja Alanija».

Tibilov, A.A. (1936). «Kosta Chetagurov». Chetagurov, K., Izbrannye stichotvorenija i poèmy (Poesie e poemi scelti). Stalinir: Gosizdat Jugo-Osetii, 7-9.

Tokazov, C.A. (1959). «Recensione di Gagkaev 1957». Učenye zapiski Severo-Osetinskogo gosudarstvennogo pedagogičeskogo instituta imeni K.L. Chetagurova (Note scientifiche dell'Istituto pedagogico dell'Ossezia settentrionale K.L. Chetagurov), 24, 241-56.

Tomelleri, V.S. (2016). «Die Latinisierung der ossetischen Schrift. Sprachliche und kulturelle Implikationen im sowjetischen Diskurs (Gedanken zu einem Forschungsprojekt)». Cotticelli-Kurras, P.; Rizza, A. (eds), Variation within and among Writing Systems. Concepts and Methods in the Analysis of Ancient Written Documents. Wiesbaden: Reichert, 303-32.

Tomelleri, V.S. (2018a). «Sessione alfabetica». Maurizio, Tomelleri 2018, 1536. http://www.ojs.unito.it/index.php/QuadRi/issue/view/318.

Tomelleri, V.S. (2018b). «Riforma alfabetica e ideologia. La ricezione del dizionario trilingue di Miller in Unione Sovietica e in Occidente». Maurizio, Tomelleri 2018, 63-84. http://www.ojs.unito.it/index.php/QuadRi/ issue/view/318.

Tomelleri, V.S.; Giordano, A. (2019). «On Translating Kosta Chetagurov's Iron Fændyr (Ossetian Harp) into Italian. Some Observations». V saertašoriso konperencia „Kartul-osur urtiertobata ganvitarebis perspekțivebi (konperencia ejğvneba Mixeil Qipiansa da Kosța Xetagurovs). Masalebi. Fifth International Scientific Conference "Development of Georgian-Ossetian Relationship». Proceedings of a Conference dedicated to Mikheil Kipiani and Kosta Khetagurov. Tbilisi: Ivane J̌avaxišvilisi saxelobis Tbilisi saxelmçipo universițeți, 149-53.

Tomelleri, V.S.; Salvatori, M.; Giordano, A. (2020). «Kosta Chetagurov. Četyre vremeni goda. Interlinearnyj morfosintaksičeskij analiz i perevod na ital'janskij jazyk» (Kosta Chetagurov. Le quattro stagioni. Analisi morfosintattica interlineare e traduzione in lingua italiana). Izvestija SOIGSI, 37(74), 71-82. http://izvestiya-soigsi.ru/current/detail.php?ID=106.

Totoev, M.S. (1951). «Publicistika i pis'ma K.L. Chetagurova» (Pubblicistica e lettere di K.L. Chetagurov). Chetagurov, K., Sobranie sočinenij v trëch tomach (Opere in tre volumi). Tom tretij, Publicistika i pis'ma (Pubblicistica e lettere). Dzaudžikau: Gosudarstvennoe izdatel'stvo Severo-Osetinskoj ASSR, 5-18.

Tuaev, D.A. (1941). Pevec narodnych dum (Cantore dei pensieri popolari). Fadeev, A.A. (a cura di), Kosta Chetagurov. Sbornik pamjati velikogo osetinskogo poèta (Kosta Chetagurov. Miscellanea in memoria del grande poeta os- 
seto). Moskva: OGIZ, Gosudarstvennoe izdatel'stvo chudožestvennoj literatury, 212-13.

Uarziati, V.S. (1997). «Osetinovedčeskie študii akademika A.I. Šegrena» (Gli studi ossetologici dell'accademico A.I. Šegren). Osetija XX veka (L'Ossezia del XX secolo), 2, 9-29.

Uarziati, V.S. (2007). «Osetinovedčeskie študii akademika A.I. Šegrena» (Gli studi ossetologici dell'accademico A.I. Šegren). Uarziati, V.S. (a cura di), Izbrannye trudy, kniga pervaja: ètnologija, kul'turologija, semiotika (Opere scelte, libro primo: etnologia, culturologia, semiotica). Vladikavkaz: ProektPress, 426-73.

Ziesche, E. (2002). Verzeichnis der Nachlässe und der Handschriftenabteilung der Staatsbibliothek zu Berlin; Preussischer Kulturbesitz. Staatsbibliothek zu Berlin; Preussischer Kulturbesitz. Kataloge der Handschriftenabteilung, herausgegeben von Eef Overgaauw. Zweite Reihe: Nachlässe, Band 8. Wiesbaden: Harrassowitz. 